\title{
REVIEWS
}

\section{Applications of guanine quartets in nanotechnology and chemical biology}

Loic Stefan $\mathbb{1}^{1 *}$ and David Monchaud (10 ${ }^{2 *}$

Abstract | Guanine and related nucleobases such as guanosine, deoxyguanosine and isoguanosine are notable molecular tools for designing functional supramolecular assemblies. This popularity originates in their ability to self-assemble via a unique topological pluralism - as isolated nucleobases, discrete macrocyclic quartets and virtually infinite linear ribbons - that endows them with a considerable functional versatility. Many programmes have been launched to fine-tune the chemical properties of guanine derivatives, to make them usable under different experimental conditions, such as in organic or aqueous environments, and responsive to external stimuli, such as ionic strength, $\mathrm{pH}$, light or temperature. These strategies aim to translate the chemical information encoded in a basic guanine unit into programmable, higher-order supramolecular architectures. Spectacular results have been recently obtained in various chemical fields, from supramolecular chemistry to chemical biology, from soft matter to catalysis. In this Review, we detail these advances and demonstrate how these multidisciplinary investigations cast a bright light on the diversity that guanines, synthetic guanines and related nucleobases uniquely offer in terms of both structure and function.

Guanines and related nucleobases such as guanosine, deoxyguanosine, isoguanosine and so on (simply referred to as $\mathrm{G}$ hereafter) are fascinating chemical tools, owing to their ability to create programmable supramolecular networks through their self-association to form G-quartets or G-ribbons, i.e. macrocyclic arrangements of four guanines or virtually infinite linear chains of guanines, respectively ${ }^{1}$ (BOX 1). These self-assembled structures are stabilized by the formation of $\mathrm{H}$-bonds at both the Watson-Crick ${ }^{2}$ and Hoogsteen ${ }^{3}$ faces, making guanine a highly versatile tool for the assembly of supramolecules, with steadily increasing applications in both nanotechnology and chemical biology.

\section{The history of guanine}

The discovery of the unique properties of guanines can be traced back to the turn of the twentieth century (FIG. 1). Stubborn scientists were determined to elucidate the chemical nature of nucleic acids ${ }^{4}$, first isolated in 1871 by Miescher ${ }^{5}$. A laborious isolation of guanylic acids from bovine pancreas was achieved by Hammarsten in 1894 (REF. ${ }^{6}$ ), but uncertainties remained as to the monomeric or polymeric nature of this novel, non-protein natural substance. Independent efforts by Levene and Jacobs ${ }^{7}$ (who coined the term tetranucleotide hypothesis) and Bang ${ }^{8}$ towards the end of the first decade of the 1900s provided ever purer guanylic acid and, in turn, solid evidence supporting the monomolecular nature of guanylic acid. They noted, as did others, the tendency of concentrated solutions to 'gelatinize' in a vivid manner, describing guanylic hydrogels as "an amorphous, somewhat gelatinous precipitate (that) turns into a semiliquid jelly"9. The precise structural nature of the viscous guanylic hydrogel linchpin was eventually unveiled by Davies and colleagues in $1962\left(\mathrm{REF}^{10}\right)$, in a report describing the very first X-ray crystal structure of a G-quartet. It seems unlikely that even the most clever of scientists would have envisioned at that time the tremendous potential of this 'semiliquid jelly' to, a century later, become a key player in supramolecular chemistry, genetics, chemical biology and catalysis.

\section{Native versus synthetic $\mathbf{G}$-quartets}

The current fascination with G-quartets undoubtedly originates from their involvement in the formation of higher-order nucleic acid structures, known as G-quadruplexes. The discovery of G-quadruplexes led to a paradigm shift in genetics because they "contribute spatial and temporal dimensionalities to linear sequence information" (Maizels) ${ }^{11}$. This paves the way for a new view of DNA in which it is not merely a barcode waiting to be scanned but actively controls its own expression according to a new - and not yet fully understood - dimensionality provided by local formation of quadruplexes. DNA then has a structurefunction relationship and joins RNA (for which this has long been accepted). In this Review, we do not aim to discuss at any length the roles of the G-quartets when 
Box $1 \mid$ H-bonded guanines

Guanine (and related guanosine, deoxyguanosine) shines by its hydrogen-bond ( $\mathrm{H}$-bond) donating/accepting capability, with three acceptor (A) and three donor (D) sites, which enables both Watson-Crick and Hoogsteen faces to participate in the creation of a broad array of $\mathrm{H}$-bond networks ${ }^{152}$. The iconic guanine/cytosine $(\mathrm{G} \equiv \mathrm{C})$ base pair follows the rule described by Watson and $\mathrm{Crick}^{2}$, involving three $\mathrm{H}$-bonds on the sole guanine's Watson-Crick face. When both faces are implicated, the supramolecular assemblies depend on the experimental conditions: in the presence of cation (e.g. $\mathrm{K}^{+}$), the guanosine $(\mathrm{G})$ quartet formation is privileged, given that alkali metals can neutralize the electrostatic repulsion of the inwardly pointing guanine's carbonyl groups within the quartet inner cavity ${ }^{1,20}$. The stability of the macrocyclic edifice thus originates in an interplay between the formation of eight $\mathrm{H}$-bonds, the cation-mediated electronic stabilization, along with the delocalization of the nucleobase electrons (resonance), either $\pi$-electrons or $\sigma$-electrons or both (the resonance-assisted hydrogen bonding $(\mathrm{RAHB})^{153}$ or the charge separation theory ${ }^{154}$, respectively). In the absence of cations, G-ribbon formation is privileged: two types of ribbon are possible (type $A$ and type $B$ ), which differ from the orientation of the guanine's molecular dipole (arising from the highly polarized aromatic surface of the nucleobase, yellow arrows $)^{1,155}$. The nature of the solvent will favour ribbon with or without global dipole moment.

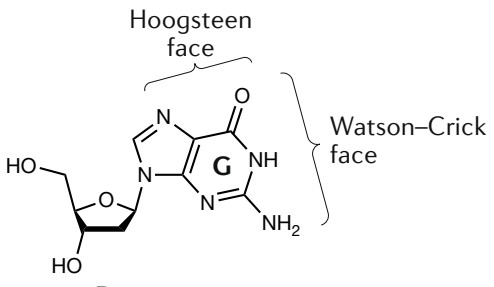

Deoxyguanosine

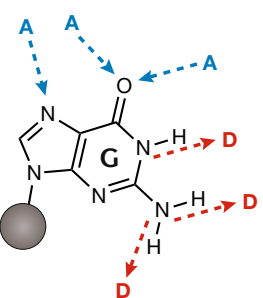

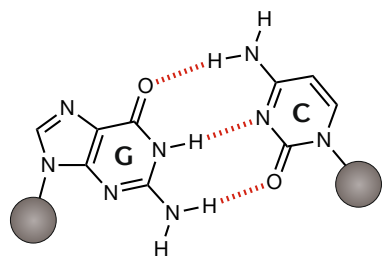

Watson-Crick base pair

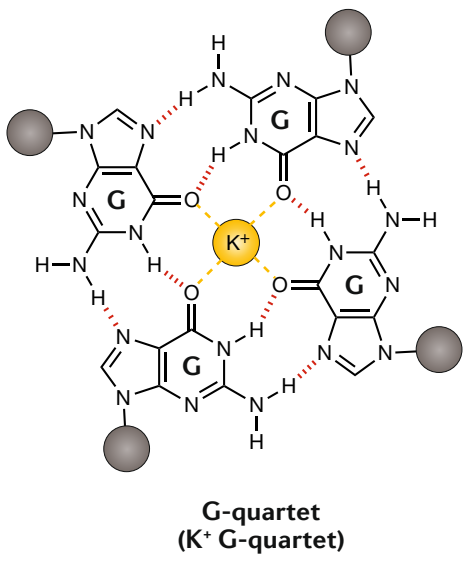

embedded in G-quadruplexes or the prevalence of quadruplex structures in the human genome, transcriptome and ncRNAome (known as $\mathrm{G} 40 \mathrm{me})^{12}$. These topics have been frequently covered in a number of other authoritative reviews ${ }^{13-17}$ and readers are directed there. Here, we focus on both natural and non-natural G-quartets or synthetic G-quartets (SQ) - used as molecular platforms for nanobiotechnological purposes.

The field of G-based molecular tools was launched in 1995 independently by Davis et al. ${ }^{18}$ and Gottarelli et al. ${ }^{19}$, who demonstrated that lipophilic guanine (LipoG) derivatives ( $5^{\prime}$-tert-butyldimethylsilyl-2', $3^{\prime}$-isopropylidene-isoguanosine (1) and 3',5'-didecanoyl$2^{\prime}$-deoxyguanosine (2), respectively; FIG. 2a) fold into stable, cation-templated SQ in organic media. In-depth NMR investigations performed with both systems indicated that potassium ions trigger the formation of higher-order assemblies, $\left[(\mathbf{1})_{4} \mathrm{~K}^{+}(\mathbf{1})_{4}\right]$ and $\left[(\mathbf{2})_{4} \mathrm{~K}^{+}(\mathbf{2})_{4}\right]$, respectively, in which the potassium ion is sandwiched

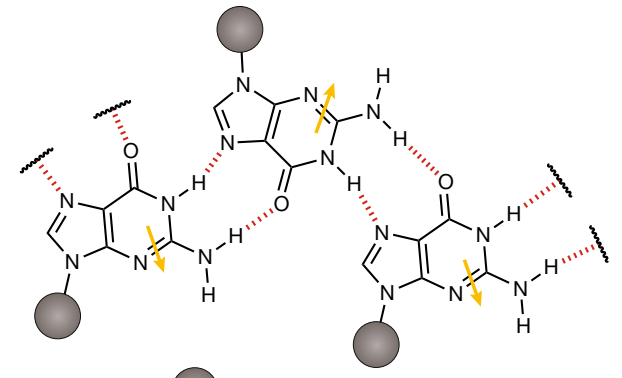

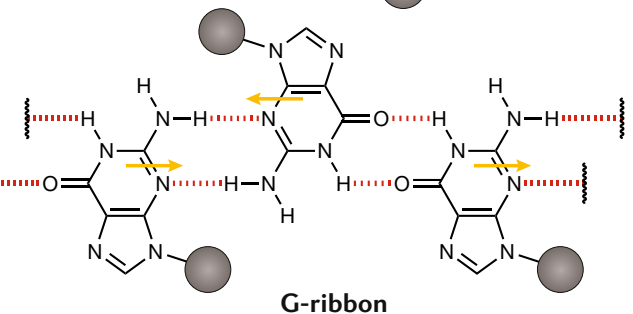

G-ribbon the G4ome comprises al G-quadruplex (G4)-forming transcriptome (G4-RNA)

LipoG

ipophilic guanine derivatives aimed at being used in organic solvents, masking hydrophilic moieties (e.g. the hydroxyl groups of the guanosine's ribose) through the use of aliphatic protecting groups. between two layers of SQ (so-called octamers; FIG. 2b). Both studies demonstrated the specific ion binding of SQ-based systems, with a better chelation of potassium $\left(\mathrm{K}^{+}, 1.33 \AA\right.$ ) versus the smaller sodium $\left(\mathrm{Na}^{+}, 0.98 \AA\right.$ ) (and no chelation for the even smaller lithium $\left(\mathrm{Li}^{+}, 0.68 \AA\right)$ ), confirming the privileged shape and charge recognition of $\mathrm{K}^{+}$by $\mathrm{G}$-based suprastructures ${ }^{20}$. Interestingly, Davis et al. soon demonstrated the importance of the chemical nature of the G-derivatives: while guanosines are selective for $\mathrm{K}^{+}$, isoguanosines selectively interact with larger cations such as caesium $\left(\mathrm{Cs}^{+}, 1.67 \AA\right)$ and radium $\left(\mathrm{Ra}^{2+}\right.$, $1.48-1.70 \AA$ ), adapting the nature of its supramolecular assembly from octamer to decamer, $\left[(\mathbf{1})_{5} \mathrm{Cs}^{+}(\mathbf{1})_{5}\right]^{21}$ and $\left[(\mathbf{1})_{5} \mathrm{Ra}^{2+}(\mathbf{1})_{5}\right]^{22}$, respectively (and, thus, from quartets to quintets). This opened the way to assemble a G-based toolbox in which to select G-derivatives in an application-driven manner (see below).

Efforts were, thus, subsequently invested to fine-tune the chemical structure of LipoGs to endow 


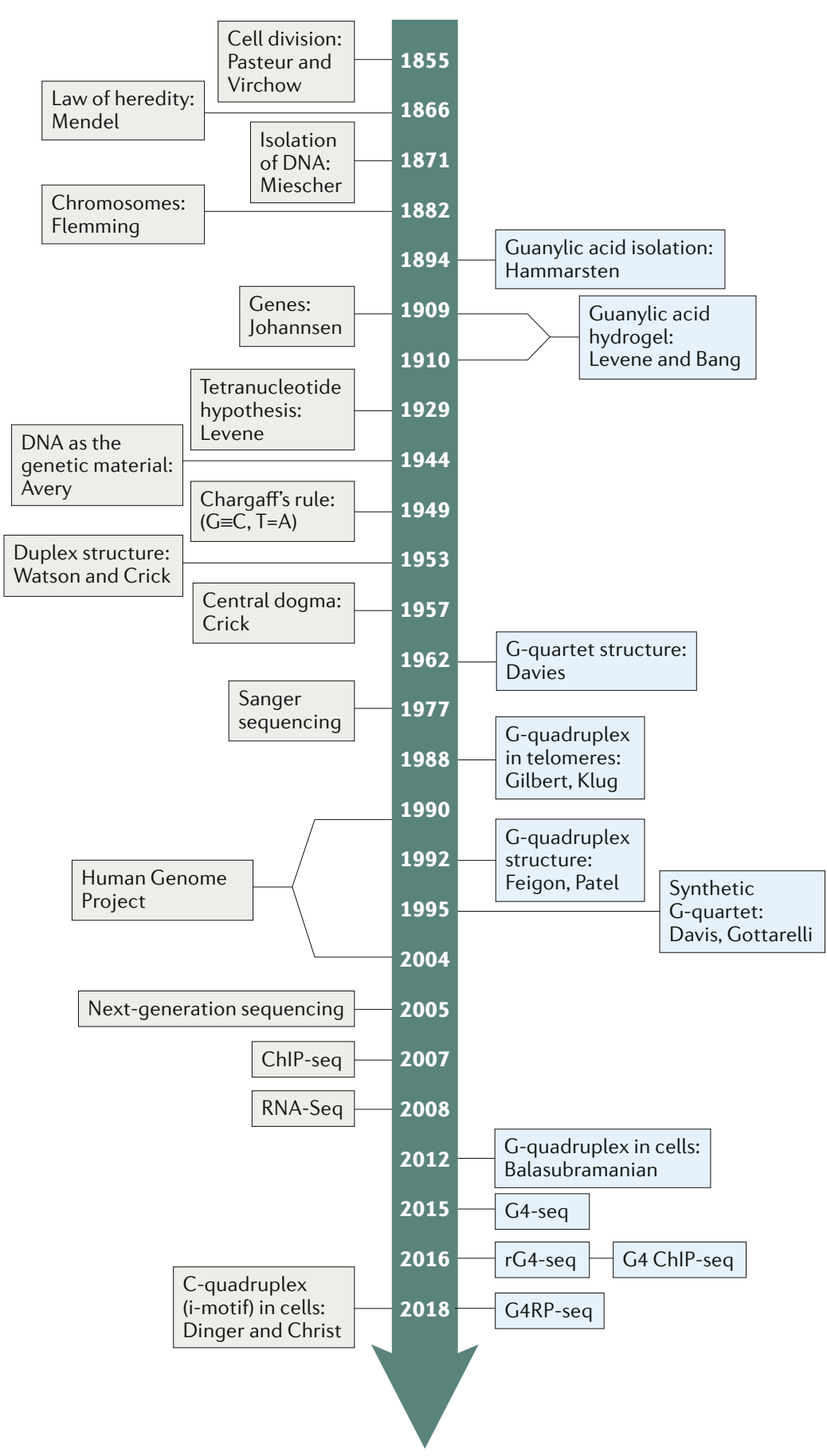

Fig. 1 | Timeline of the major steps in the discovery of DNA and G-quartets. From the first observation by Pasteur and Virchow on cell division (discarding the notion of 'spontaneous generation'), the history of DNA is marked by many important breakthroughs (grey boxes), chief among them the isolation of DNA ('nuclein') by Miescher ${ }^{156}$, the demonstration of its role as a repository of genetic information by Avery $^{157}$, the elucidation of its duplex structure by Watson and Crick ${ }^{2}$ and the central dogma of biology heralded by rrick $^{158}$. Our understanding of G-quartets has developed alongside, while also being fully part of the history of DNA, with its own important steps (blue boxes): the isolation of guanylic acid by Hammarsten ${ }^{6}$, the description of guanylic hydrogel by Levene ${ }^{7}$ and Bang ${ }^{8}$, the elucidation of the guanosine (G)-quartet structure by Davies ${ }^{10}$, the first $\mathrm{G}$-based devices by Davis ${ }^{18}$ and Gottarelli $^{19}$, and the demonstration of the existence of G-quartet-based suprastructures referred to as $\mathrm{G}$-quadruplexes in human cells by Balasubramanian ${ }^{159,160}$. them with special properties. For instance, Rivera and colleagues designed monomeric guanines that self-assemble into SQ with an extended H-bond network (increasing from 8 to $12 \mathrm{H}$-bonds) ${ }^{23}$ to improve their stability. They synthesized a LipoG derivative with an expanded Hoogsteen face, adding an acetylphenyl appendage on its C8-position (8-(3-acetylphenyl)-( $3^{\prime}, 5^{\prime}$-bis-isobutyryl)-2-deoxyguanosine (3); FIG. 2a). This allows for the formation of a synthetic G-quartet in which the amine moieties located in the outer side of the $S Q$, and, thus, readily accessible to $\mathrm{H}$-bond-donating group $\mathrm{s}^{24}$, are involved in additional intramolecular interactions. In addition to higher stability, the resulting SQ display extended $\pi$-surfaces that result in the formation of $\mathrm{K}^{+}$-promoted hexadecameric columnar assemblies $\left(\left[(3)_{4} \mathrm{~K}^{+}(3)_{4} \mathrm{~K}^{+}(3)_{4} \mathrm{~K}^{+}(3)_{4}\right]\right)$. These assemblies can be topologically switched to octameric assemblies by replacing $\mathrm{K}^{+}$with strontium $\left(\mathrm{Sr}^{2+}\right.$, $\left.\left[(3)_{4} \mathrm{Sr}^{2+}(3)_{4}\right]\right)^{25}$, in a reversible manner, on the basis of electrostatic consideration only (FIG. 2c). Spada and colleagues also exploited the strategic $\mathrm{C} 8$-modification of LipoGs to introduce a photo-switchable styryl moiety $\left(3^{\prime}, 5^{\prime}\right.$-O-diacetyl-8-styryl-guanosine (4); FIG. 2a), which enables control over the $\mathrm{K}^{+}$-promoted formation of the $\left[(\mathbf{4})_{4} \mathrm{~K}^{+}(\mathbf{4})_{4}\right]$ octamers and their light-induced disassembly ${ }^{26}$. Irradiation at $\lambda_{\mathrm{ex}}=365 \mathrm{~nm}$ indeed triggers the $E$-to- $Z$ conformational switch of the 8-styryl-guanosine, creating a steric clash that precludes $\pi$-stacking interactions between SQ planes and, thus, causes the supramolecular complex to disaggregate. Upon irradiation at $\lambda_{\text {ex }}=254 \mathrm{~nm}$, the conformational switch is reversed ( $Z$-to- $E$ conversion) and the octamer restored, making the system fully reversible (no cycling wastes) and controllable (FIG. 2d). C8-modified LipoGs were also useful for gaining insights into the many external factors that influence the topological dynamism of resulting SQ. Using 8-bromo-2',3'-O-isopropylidene$5^{\prime}$-tert-butyldimethylsilyl-guanosine (5) (FIG. 2a), Meijer and colleagues confirmed the expected roles of solvent polarity and of the nature of the cation, but also highlighted a subtle yet significant influence of the Coulombic energy of cation-anion pairs (e.g. $\mathrm{KCl}, \mathrm{KBr}$ or $\mathrm{KI}$ ) used for templating SQ formation ${ }^{27}$. Ion pair-separation energy, although largely negligible in water, is important in organic buffers, given that it may have an impact on the nature of the resulting supramolecular assemblies (octamers, dodecamers or hexadecamers). Brown and colleagues further substantiated these observation ${ }^{28}$, demonstrating that the topological pluralism of LipoG might also be subtly influenced by the method of investigation (in this case, the differences between solution and solid-state NMR), highlighting again the need to exercise caution when studying highly dynamic supramolecular systems. Anecdotally, $\mathbf{5}$ was a synthetic intermediate in a strategy implemented by Davis and colleague to take control over the topological diversity of G-based assemblies ${ }^{29}$. Attempting to irreversibly freeze octamers via covalent crosslinking, alkene appendages were inserted on the $\mathrm{C} 8$ and $\mathrm{N} 2$ positions of $\mathbf{5}$. The resulting $\mathrm{Ba}^{2+}$-promoted octamer was then subjected to olefin metathesis, but this very elegant strategy proved unsuccessful. 


\section{REVIEWS}

a<smiles>CC1(C)OC2(CO[Si](C)(C)C(C)(C)C)OC(n3cnc4c(N)[nH]c(=O)nc43)(O1)O2</smiles><smiles>CC(=O)OCC12CC(O1)N1C=Nc3c(nc(N)[nH]c3=O)N1C2</smiles><smiles></smiles><smiles>CC1(C)OC2(CO[Si](C)(C)C(C)(C)C)OC1O2</smiles>

b<smiles>CC(=O)OCC1OC(n2cnc3c(=O)[nH]c(N)nc32)CC1OC(=O)C1CC1</smiles>

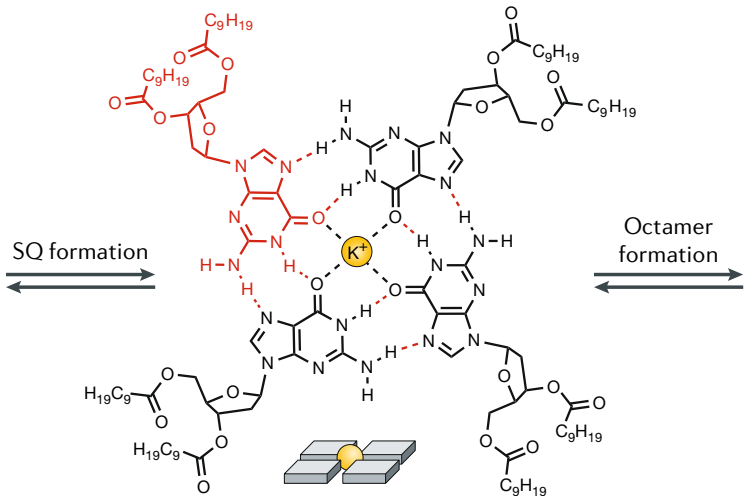

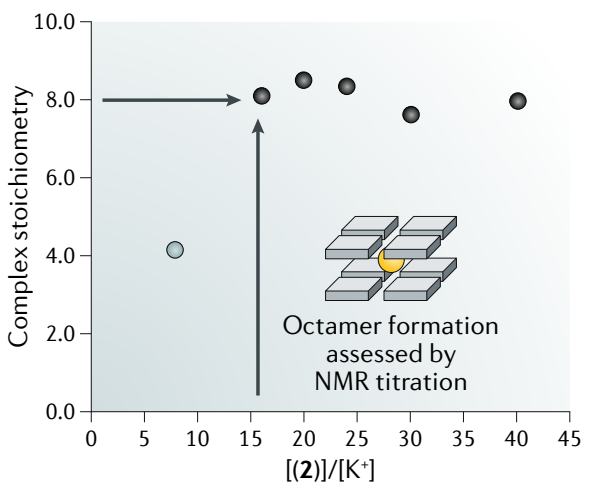

c<smiles></smiles>

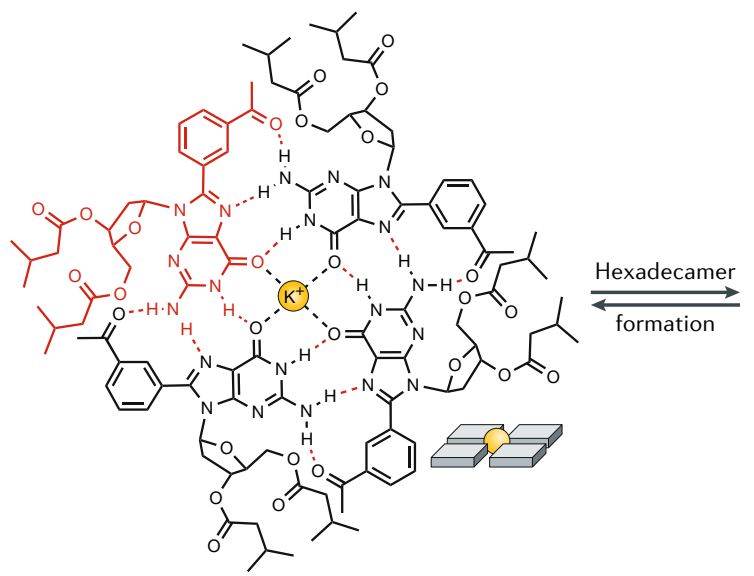
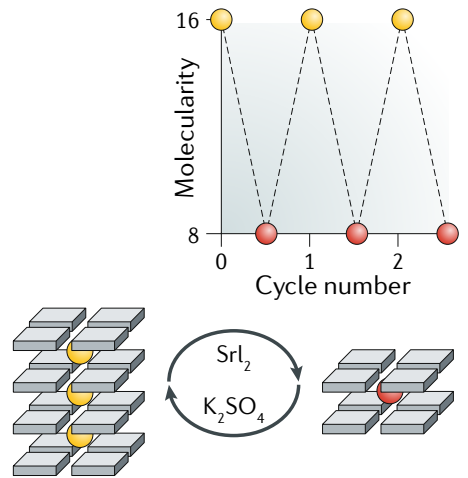

d
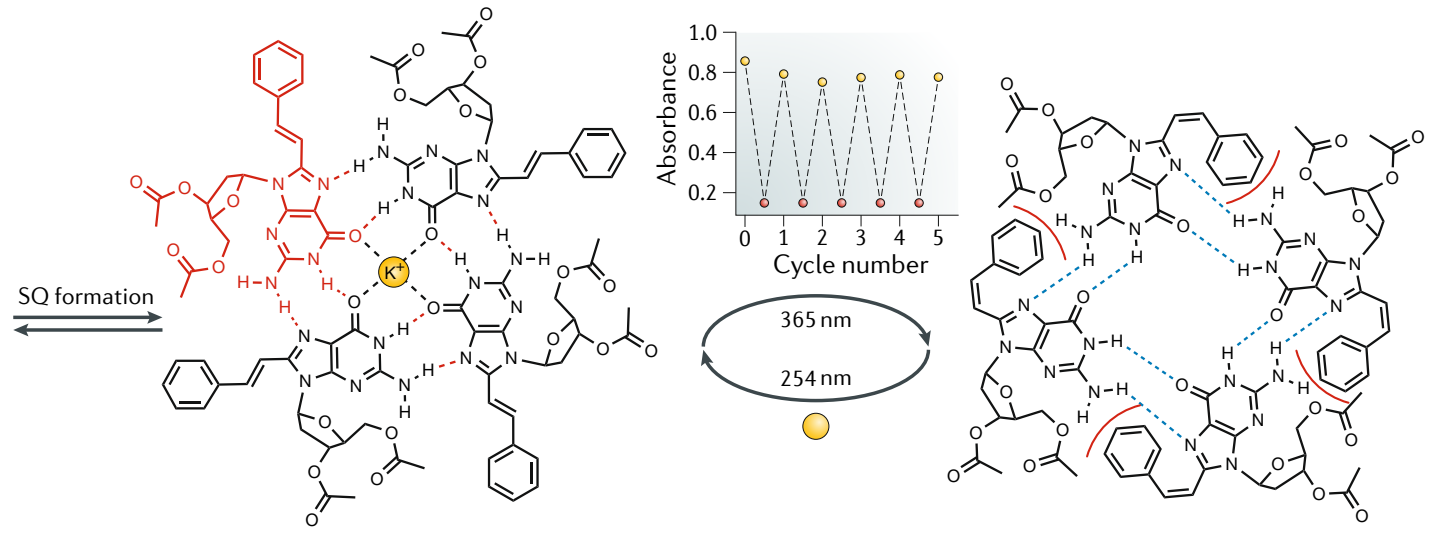

Fig. 2 | LipoGs and their higher-order supramolecular assemblies. a | Monomeric lipophilic guanosines (LipoGs) investigated by Davis (1) $)^{18}$, Gottarelli (2) $)^{19}$, Rivera (3) $)^{23}$, Spada $(\mathbf{4})^{26}$ and Meijer (5) $)^{27}$ used as models to gain insight into the parameters that govern $\mathrm{G}$-quartet formation. $\mathbf{b}, \mathbf{c}$ | LipoGs $(\mathbf{2}, \mathbf{3})$ were used to demonstrate the capacity of $\mathrm{K}^{+}$-promoted G-quartets to adopt higher-order suprastructures, such as octamers and hexamers. $\mathbf{c}, \mathbf{d} \mid$ A variety of strategies were implemented to gain control over G-quartet topological pluralism (tetramer, octamer, hexadecamer), in a reversible manner, using either metallo-responsive or light-responsive LipoGs. SQ, synthetic G-quartets. 


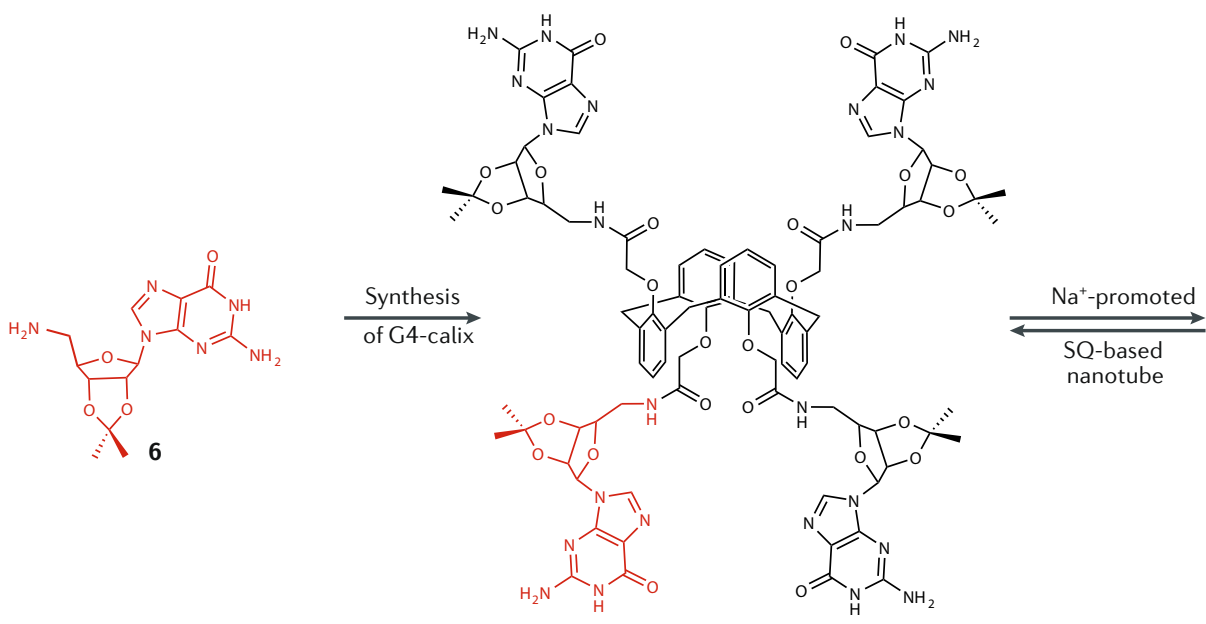

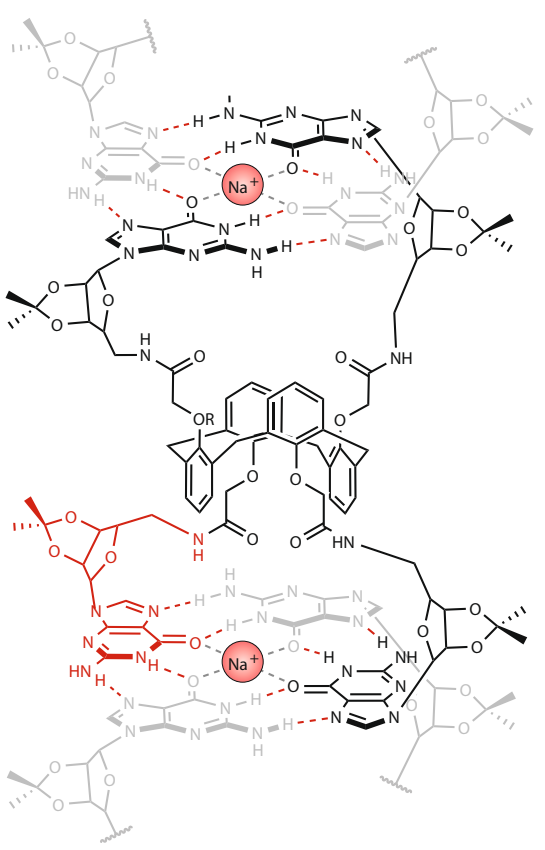

b

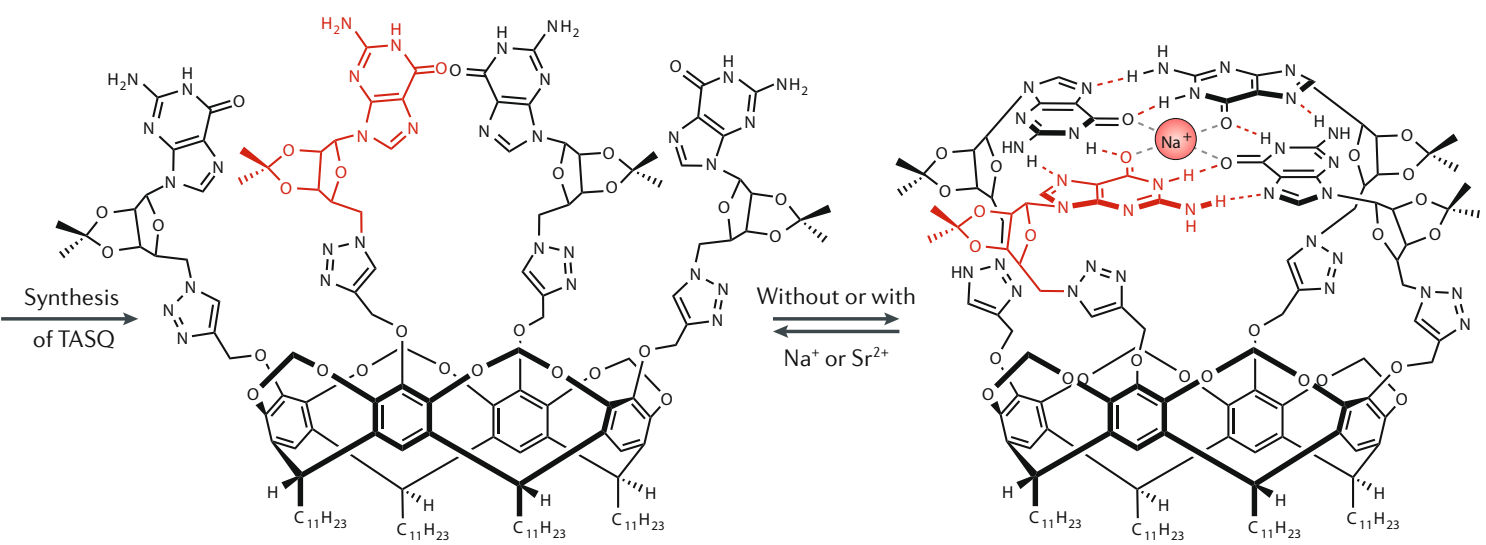

Fig. 3 | Tetrameric lipophilic guanosines assemblies. a | Guanosine (G)4-calix synthesis from (6) ${ }^{32}$ and spontaneous, $\mathrm{Na}^{+}$-promoted self-association leading to the formation of nanotubes based on the intermolecular synthetic $\mathrm{G}$-quartets (SQ) thanks to the alternate (up-down-up-down) orientation of the 1,3-alt-calix[4]arene template. $\mathbf{b}$ | Template-assembled synthetic G-quartets (TASQ) synthesis from (7) ${ }^{34}$ and representation of its 'open' (centre) and 'closed' (right) conformation, in which an intramolecular SQ is folded, owing to the all-up orientation of the cavitand template.

It was later revisited and applied efficiently for the synthesis of artificial ion transporters (see below).

A further possibility that enables greater control over the nature of the G-quartet-based suprastructures is to assemble multiple guanines within the same chemical scaffold. Lipophilic G-dimers and G-tetramers were designed to construct higher-order assemblies in a precise manner. The self-assembly of a covalently tethered C8-aryl G-dimer derived from 5 led to discrete quadruplex-type octamers (whose structure was confirmed by single-crystal X-ray diffraction). The resulting structures were found to be highly stable, even in protic (methanol, up to $100 \%$ ) or polar aprotic (dimethyl sulfoxide, DMSO, up to $50 \%$ ) solvents ${ }^{30}$. To build supramolecular ion channels, Matile and colleagues synthesized G-dimers to assemble artificial ion channels but faced tremendous solubility issues, which likely originated from the use of non-glycosylated purine moieties ${ }^{31}$. Davis and colleagues successfully addressed this issue, assembling four $5^{\prime}$-amino- $2^{\prime}, 3^{\prime}$-isopropylideneguanosines (6) around an alternating calix[4]arene scaffold $^{32}$. The resulting G4-calix (FIG. 3a) orientates two guanines above and two guanines below the plane defined by the calixarene core (in an 'up-down-up-down' manner), so that the spontaneous, $\mathrm{Na}^{+}$-promoted assembly of multiple G4-calix moieties results in the formation of micrometre-long, SQ-based nanotubes. Sherman and colleague followed a similar approach, using the alkyne-azide cycloaddition to attach four $5^{\prime}$-azido- $2^{\prime}$, $3^{\prime}$-isopropylidene-guanosines (7) to a Cram-bowlshaped cavitand displaying four propargyloxy groups ${ }^{33}$ to assemble lipophilic G-tetramers, referred to as TASQ (template-assembled synthetic G-quartets) ${ }^{34}$. The all-up organization of the cavitand template makes TASQ the first example of discrete, intramolecular SQ. The presence of cations is not mandatory for the SQ formation; however, TASQ efficiently chelate $\mathrm{Na}^{+}$or $\mathrm{Sr}^{2+}$, in a complex in which the quartet acts as a lid on top of a 
basket-like ion receptor (FIG. 3b), while larger cations such as $\mathrm{Cs}^{+}$trigger TASQ dimerization [(TASQ) $\mathrm{Cs}^{+}$(TASQ) $]^{35}$.

\section{Lipophilic versus water-soluble G-quartets}

LipoGs have been instrumental in understanding the factors that govern G-quartet formation and stability, thanks to the broad variety of techniques implementable in organic solvents that are often more challenging to apply in water (see below). However, water-soluble guanines open up opportunities in terms of applications, notably for investigations in biological systems. From a structural point of view, the simplest hydrophilic monomer is guanosine monophosphate (GMP; FIG. 4). Early investigations on G-quartet formation were performed using concentrated GMP solutions $\left(25 \mathrm{mg} \mathrm{mL}^{-1}\right)^{10}$. The structure of GMP-based, hydrophilic G-quartets was further investigated later on, through modern analytical techniques. For instance, using a combination of scanning electron microscopy (SEM) and NMR, Walmsley and colleagues demonstrated that $\mathrm{Na}^{+}$indeed prompts GMP to form G-quartets $\left[(\mathrm{GMP})_{4} \mathrm{Na}^{+}\right]$that then spontaneously self-assemble into micrometre-length rods comprising thousands of stacked G-quartets. Meanwhile, $\mathrm{K}^{+}$leads to the formation of both rod-like lattices (formed of stacked $\left[(\mathrm{GMP})_{4} \mathrm{~K}^{+}\right]$, similar to those formed with $\mathrm{Na}^{+}$) and twisting fibres comprising continuous helices of hydrogen-bonded guanines, with $15 \mathrm{Gs}$ per turn ${ }^{36}$ (FIG. 4a). The puckering of both the $\mathrm{C} 2$ '-endo/C3'-endo sugars alternates along the strands and the right-handed helical twist of the suprastructure were confirmed by Wu et al., using a combination of $1 \mathrm{D}$ and 2D NMR spectroscopy techniques ${ }^{37,38}$. GMP-dimers and GMP-tetramers have also been investigated. For example, the naturally occurring GMP-dimer c-di-GMP ${ }^{39}$, which is a central bacterial messenger, was not observed to fold into G-quartets or G-quadruplexes under the conditions found inside cells ( $300 \mathrm{mM} \mathrm{K} \mathrm{K}^{+}$and $10 \mathrm{mM} \mathrm{c}$-di-GMP). This observation discounts any possible biological role of c-di-GMP higher-order assemblies in the bacterial cell cycle. However, the presence of substoichiometric quantities of aromatic intercalators (such as proflavine $\mathrm{e}^{39}$ or thiazole orange $\mathrm{e}^{40}$; FIG. 4b) leads to the formation of highly stable c-di-GMP quadruplexes with a cage-like structure in which the aromatic inducer is intercalated between two layers of G-quartets. Sherman and colleagues scrutinized the structure of tetrameric GMP, following the lipophilic TASQ approach and exploiting the phosphate group of the $2^{\prime}$-deoxyguanosine- $3^{\prime}$-monophosphate to link guanines to the cavitand template ${ }^{41}$ (FIG. $4 \mathrm{C}$ ). As above, the presence of cations is not mandatory for the G-quartet formation of water-soluble TASQ; this new molecular tool was not exploited for cation chelation but as a DNA-mimicking platform to investigate the interactions between G-quartets and G4-ligands (vide infra).

Overall, the wealth of information collected over the past 25 years with both lipophilic and hydrophilic G-quartets has provided invaluable insights into the thermodynamic, dynamic and structural parameters that govern the assembly of G-quartet structures. The analytical techniques available to study these structures have become increasingly effective and accurate, making the area a playground for the development and application of cutting-edge technologies. From the pioneering crystallographic works of Gellert et al. ${ }^{10}$ that provided the very first details about the structure of a G-quartet, many different practical and theoretical techniques (often combined) have been applied to gain insights into the kinetics and thermodynamics of G-based assemblies. This includes other X-ray-based techniques (for example, small-angle X-ray scattering $(\mathrm{SAXS}))^{42}$, along with various microscopy techniques: atomic force microscopy (AFM) was applied to characterize the self-organization of GMP on mica ${ }^{43}$, SEM was applied to investigate the folding parameters and global topology of micrometre-long $\mathrm{Na}_{2}\left(5^{\prime}\right.$-GMP) assemblies ${ }^{36}$ and scanning tunnelling microscopy (STM) was applied in combination with density functional theory (DFT) calculations to assess whether and how G-quartets can be assembled on surfaces (either $\mathrm{Au}(\mathrm{III})^{24,44}$ or highly oriented pyrolytic graphite (HOPG $)^{45}$ surface) in solventless conditions, with simple or sophisticated guanine derivatives, in the absence or presence of $\mathrm{Na}^{+}, \mathrm{K}^{+}$or $\mathrm{Ca}^{2+}$ cations. Spectroscopic techniques provided invaluable clues about G-based self-assemblies in solution; these include Fourier transform infrared (FTIR) ${ }^{46}$, infrared multiple photon dissociation (IRMPD) ${ }^{47-49}$ and RAMAN $^{50}$ spectroscopies, along with electronic and vibrational circular dichroism for instance (ECD ${ }^{51}$ and $\mathrm{VCD}^{52}$, respectively) combined with degenerate coupled oscillator (DCO) calculations ${ }^{52}$ and $\mathrm{NMR}^{53,54}$, notably diffusion-ordered spectroscopy (DOSY) NMR, which were successfully implemented to characterize the cation-templated GMP aggregation in near-physiological conditions. Finally, theoretical models were provided via molecular dynamics $(\mathrm{MD})^{55,56}$ and molecular mechanics (MM) ${ }^{57}$, notably for both describing cation-templated G-quartet formation and simulating in silico the movement (channelling) of cation (e.g. $\mathrm{K}^{+}$) between two G-quartet layers. Dispersion-corrected DFT was also found to be a quantum chemical computational method of choice for deciphering the parameters (desolvation energy, cation size) at the origin of the exquisite $\mathrm{K}^{+}$affinity of G-quartets ${ }^{58,59}$. This wealth of information has been progressively harnessed to design ever more versatile G-based molecular tools that have found applications in the fields of soft matter, nanotechnology and chemical biology, which will be discussed in the following sections.

\section{Nanotechnological applications}

As described above, the first application developed with guanines relied on their capability to firmly chelate cations. Lipophilic SQ were thus exploited as ionophores, capable of extracting cations from water into organic solvents (most often chlorinated solvents, such as chloroform or dichloromethane). Model studies were performed with $\mathrm{K}^{+}$and $\mathrm{Na}^{+}$, but the demonstration that G-quartets efficiently chelate radioactive metals such as caesium $\left({ }^{137} \mathrm{Cs}^{+}\right)$and radium $\left({ }^{226} \mathrm{Ra}^{2+}\right)$ generated a tremendous strategic interest. Notably, it was shown that the isoguanosine derivative (1) could self-assemble to form nanoscale decamers that were capable of capturing $\mathrm{Cs}^{+}\left(\left[(\mathbf{1})_{5} \mathrm{Cs}^{+}(\mathbf{1})_{5}\right]\right)$ and $\mathrm{Ra}^{2+}\left(\left[(\mathbf{1})_{5} \mathrm{Ra}^{2+}(\mathbf{1})_{5}\right]\right)$, even in the presence of a million-fold excess of other cations $\left(\mathrm{Na}^{+}, \mathrm{K}^{+}, \mathrm{Mg}^{2+}\right)^{21,22}$, and, thus, suggesting a possible new application in the remediation of nuclear wastes. 
<smiles>Nc1nc2c(ncn2C(O)C(O)C(O)COP(=O)([O-])O)c(=O)[nH]1</smiles>

(5'-monophosphate)

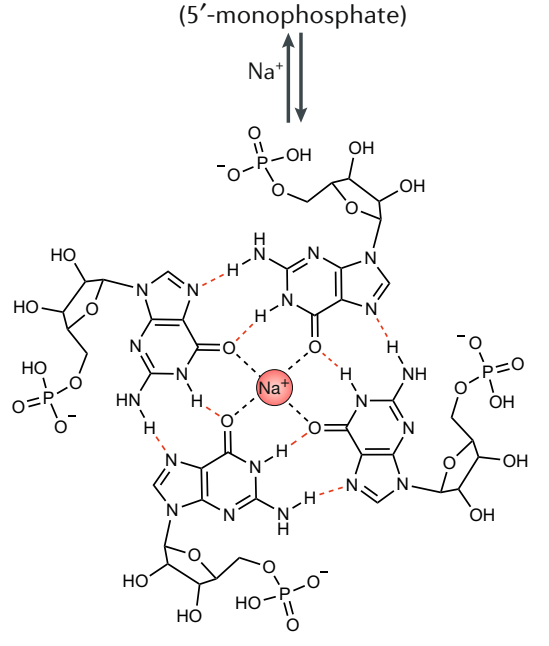

b

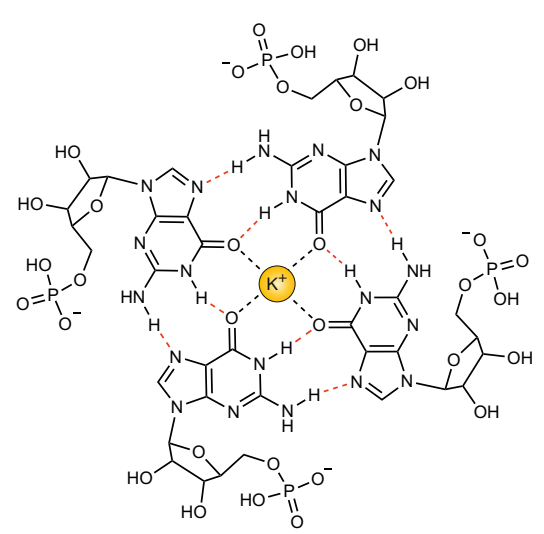

(1)
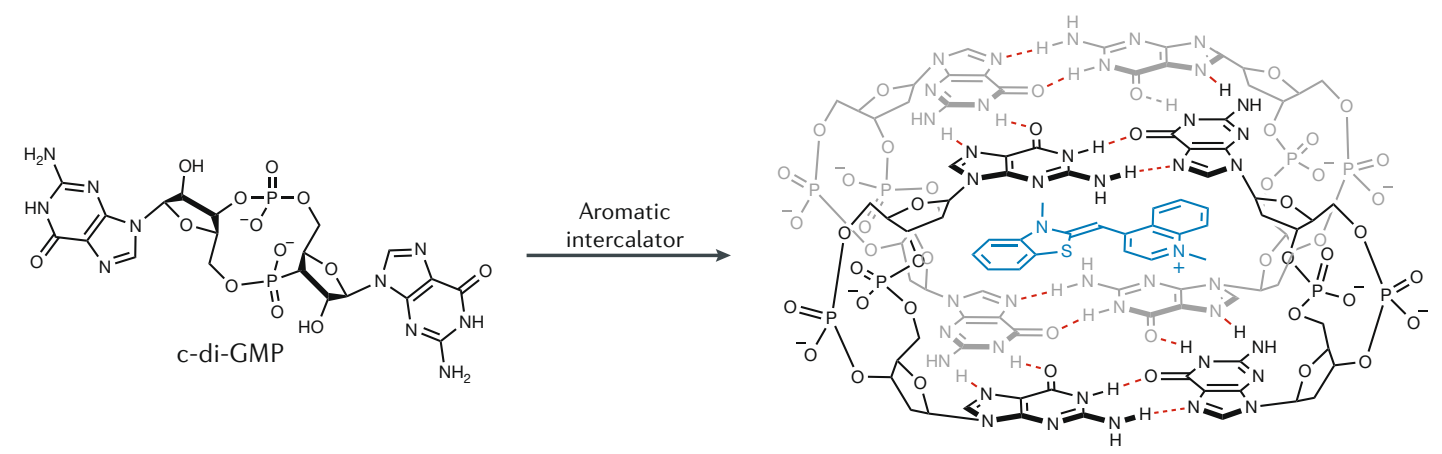

c

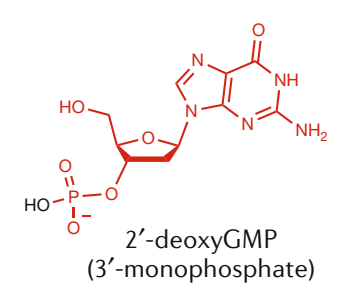<smiles></smiles>

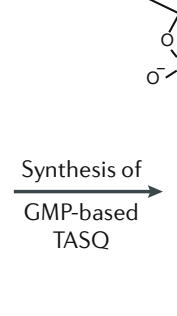

Oip=0<smiles>Nc1nc2[nH]cnc2c(=O)[nH]1</smiles>

Fig. 4 | Structural studies of water-soluble G-assemblies. a | Monomeric guanosine monophosphate (GMP) can self-assemble in discrete G-quartets in the presence of $\mathrm{Na}^{+}$and $\mathrm{K}^{+}$, but the latter can also trigger the formation of micrometre-long, helical rod-like structures comprising continuous, open-ended G-quartet ${ }^{36}$. b | The dimeric GMP c-di-GMP can form $\mathrm{G}$-quadruplexes comprising four c-di-GMP molecules upon interaction

with aromatic inducers (here, thiazole orange) that intercalate between two layers of G-quartets ${ }^{40}$. c | Tetrameric GMP can be assembled intramolecularly to provide water-soluble template-assembled synthetic G-quartets (TASQ) that fold into intramolecular SQ without cations and serve as a platform for investigating the G-quartet interactions of G4-ligands (here, BRACO-19) ${ }^{41}$. 


\section{REVIEWS}

a

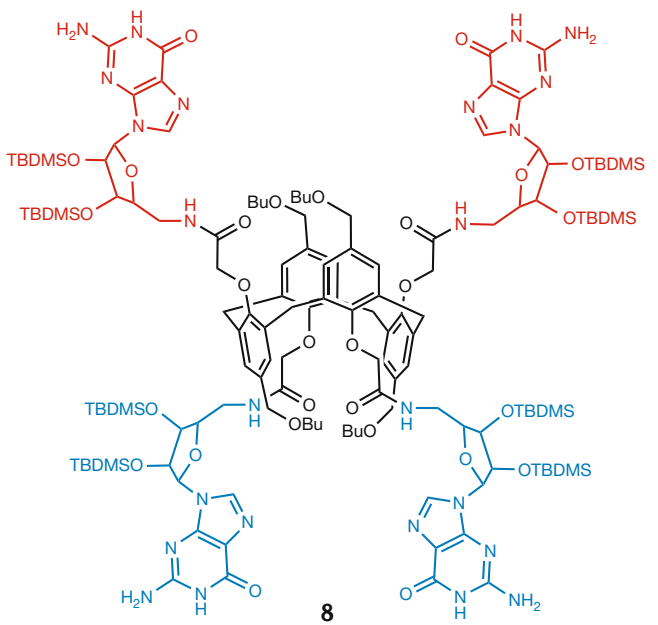

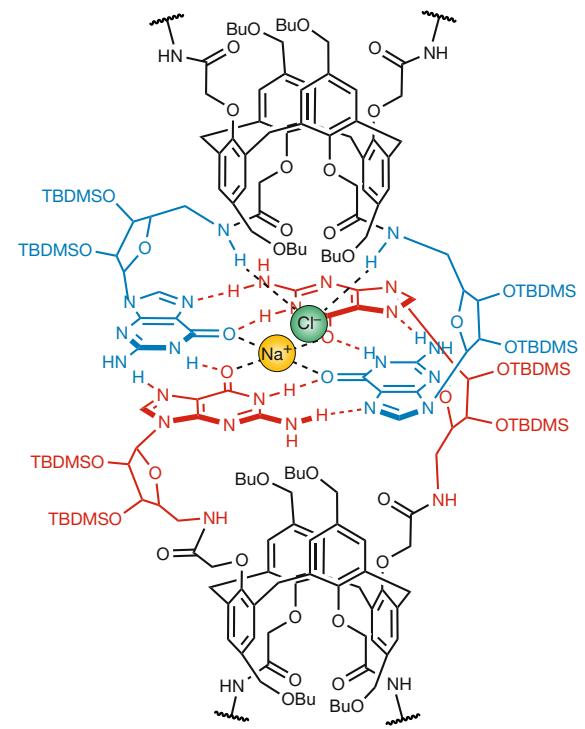

b<smiles>C=CCOc1cc(OCC=C)cc(C(=O)OCC23COC(n4cnc5c(=O)[nH]c(N)nc54)(OC2(C)C)O3)c1</smiles>

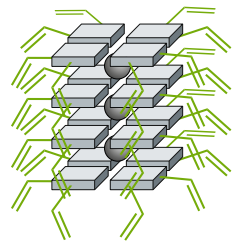

Olefin $\stackrel{\text { metathesis }}{\longrightarrow}$
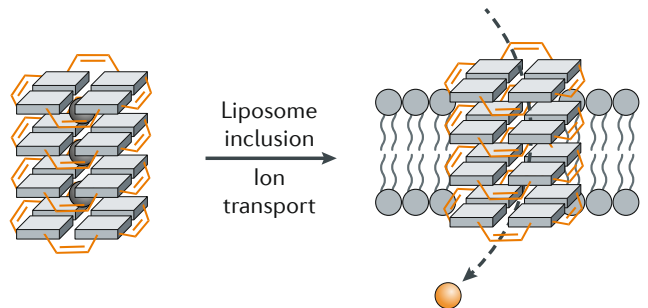

C
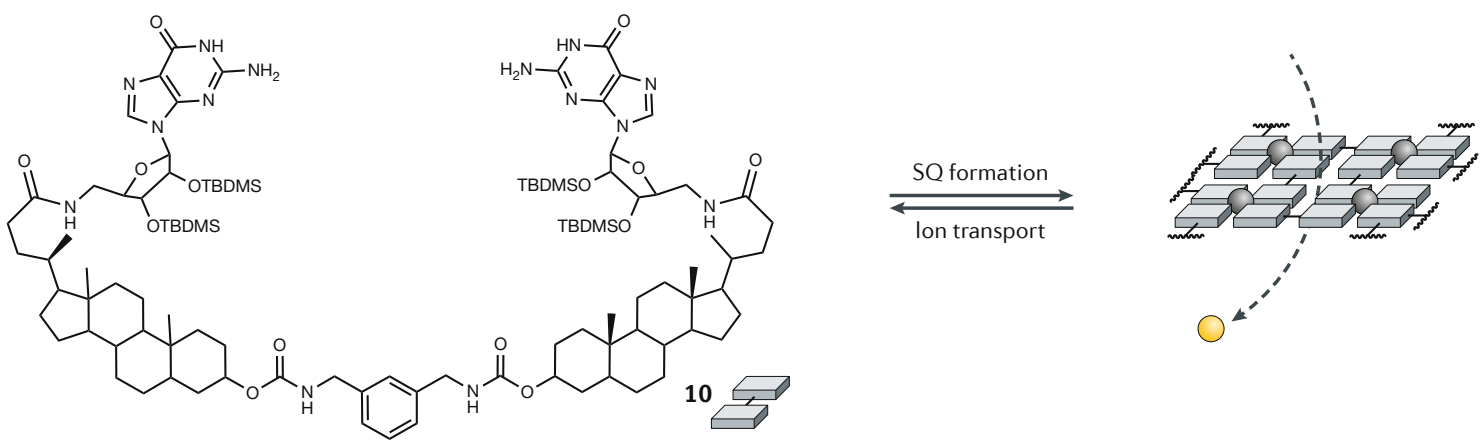

Fig. 5 | Applications of G-quartet-based devices as ionophores and ion channels. a | Artificial ion pair (NaCl) receptor that results from the dimerization of 1,3-alt-calix[4] arene-templated guanosine (G)-tetramer $(\mathbf{8})^{60}$. $\mathbf{b} \mid \mathrm{A}$ covalently crosslinked quadruplex, comprising 16 units of the $\mathrm{G}$-monomer $(\mathbf{9})^{62}$ linked via olefin metathesis, acts as a $\mathrm{Na}^{+}$transporter through inclusion in a liposome membrane. c| The lipophilic, bis-lithocholamide-based G-dimer (10) ${ }^{65}$ self-associates to form synthetic G-quartets (SQ)-based nanopores that allow for $\mathrm{K}^{+}$transportation through phospholipid bilayers.

Davis and colleagues later developed ionophores with improved chelating properties, providing binding sites for both cations and anions ${ }^{60}$. The dimeric assembly of 1,3-alt-calix[4]arene-templated G-tetramer (8) indeed traps $\mathrm{Na}^{+}$within the intermolecular SQ plane, while $\mathrm{Cl}^{-}$is chelated by two neighbouring amide groups (FIG. 5 a). This study, performed in water-saturated chloroform, highlighted the key role of water in the overall stability of the supramolecular edifice, lowering the energy required for extracting the ions from bulk water to the ionophore's binding site, participating in salt binding between the quartet layers and filling the coordination spheres of bound ions.

Lipophilic SQ were also exploited as ion channels ${ }^{61}$ their lipophilicity means that they are readily incorporated into membranes. Davis and colleagues constructed transmembrane pores based on a quadruplex architecture. These pores were formed by the assembly of the G-monomer 5'-(3,5-bis(allyloxy)benzoyl)-2', $3^{\prime}$-isopropylidene guanosine (9), followed by crosslinking of neighbouring guanines within the quadruplex architecture using ruthenium-catalysed, ring-closing metathesis $^{62}$ (FIG. 5b). This approach leads to a covalently crosslinked quadruplex that avoids any potential problems arising from the dynamic nature of quadruplex formation/disassembly. The capacity of the resulting quadruplex, comprising sixteen units of (9), to transport $\mathrm{Na}^{+}$across a liposome membrane was qualitatively demonstrated by both base-pulse assay and ${ }^{23} \mathrm{Na}$ NMR spectroscopic experiments. 
The approach of covalently capturing the formed quadruplexes was subsequently extended using a photocycloaddition strategy. Combining 2',3'-isopropylidene guanosine moieties with meta-methoxycinnamic acid provided G-monomeric units primed for crosslinking. Once assembled in SQ in the presence of $\mathrm{K}^{+}$, an UV-promoted [2+2] cycloaddition of the cinnamate chains led to the formation of cyclobutane covalent crosslinks with high chemical yields $(>90 \%)^{63}$. However, the ion-transportation properties of these new suprastructures were not assessed. Matile and colleagues exploited another type of lipophilic SQ to assemble ion channels, using $\pi$-stacked supramolecular rosettes made of G-mimicking folate quartets ${ }^{64}$. The capacity of the obtained channels to transport $\mathrm{K}^{+}$across lipid bilayers highlights the importance of the dynamic nature of quartet-based channels, which uniquely allows for sterically demanding cations to be transported through topologically breathing channels, an effect termed dynamic ion tunnelling. Davis and colleagues also constructed ion channels whose structure relies on the assembly of preformed G-dimers covalently linked by bis-lithocholamide linkers (10) ${ }^{65}$ (FIG. 5c). The capacity of these pores to enable $\mathrm{K}^{+}$transport across phospholipid bilayers was quantified by conductance experiments. It was, thus, shown that the resulting SQ channels formed in this way were heterogeneous in size, with small, 2.6- $\AA$-diameter pores (with a corresponding conductance in the $\mathrm{pS}$ range) that correspond to discrete SQ and large, 12 - $\AA$-diameter pores (with conductance in the $\mathrm{nS}$ range) that correspond to polymeric SQ (as shown in FIG. $5 \mathrm{c}$ ). Dash and colleagues subsequently combined these different approaches, linking lipophilic G-dimers using various bridge structures (polyethylene glycol (PEG), dyes, aromatic linkers) ${ }^{66,67}$ to assemble channels that could embedded within phospholipid bilayers and capable of transporting cations such as $\mathrm{K}^{+}$for long durations (up to $10 \mathrm{~h}$ ).

Moving beyond ion transportation, G-quartet structures have also been exploited for the construction of functional nanostructures. For instance, Dash and colleagues exposed GMP to microwave-assisted thermal treatment in order to assemble carbon dots ${ }^{68}$. While GMP itself does not possess interesting spectroscopic properties, these so-called G-dots were found to have interesting fluorescence upconversion properties and can be readily converted in fluorescent G-dot hydrogels in the presence of $\mathrm{K}^{+}$, which were shown to have high thermal stability (gel-sol transition temperature $>70^{\circ} \mathrm{C}$ ) and elasticity. Meijer and colleagues used LipoGs to assemble fluorescent organic nanoparticles (ONP) (FIG. 6a). Cation-templated self-assembly of oligo( $p$-phenylene vinylene) (OPV) guanosines (11) leads to disc-shaped octameric nanostructures ( $1.5 \mathrm{~nm}$ high, $8.5 \mathrm{~nm}$ wide), with improved fluorescence emission properties in comparison with isolated guanosines (with a twofold to threefold enhancement of quantum yield in organic solvents) and thermal stability (melting temperature $\left.>70^{\circ} \mathrm{C}\right)^{45}$. Mirkin and colleague also exploited G-quartet formation to assemble metallic nanoparticles (FIG. 6b). A disperse solution of 10 -nm gold nanoparticles coated with $3^{\prime}$-thiopropyl-GMP (12) were combined with a series of short, G-rich oligonucleotides to produce, upon $\mathrm{Na}^{+}$addition, micrometre-long architectures that displayed increased plasmon coupling as a result of reduced interparticle distance and higher thermal stability (aggregate-sol transition temperature $>60^{\circ} \mathrm{C}$ ) ${ }^{69}$. $\mathrm{Wu}$ and colleagues assembled even larger nano-objects by subjecting concentrated GMP solution (33 wt $\%$, i.e. $800 \mathrm{mM})$ to weakly basic conditions $(\mathrm{pH}=8)$, which results in the formation of $\mathrm{Na}^{+}$-containing nanocylinders (26 $\AA$ diameter, up to $30 \mathrm{~nm}$ long ${ }^{70}$. Qu and colleagues later demonstrated that replacing $\mathrm{Na}^{+}$for $\mathrm{Sr}^{2+}$ enabled the production of micrometre-long nanowires from diluted GMP solution $(20 \mathrm{mM})$, in a reversible, controllable manner (nanowires were broken upon the addition of EDTA $)^{71}$. Decorating these fibres with three dyes, i.e. thioflavin $\mathrm{T}$, thiazole orange and pyronin $\mathrm{Y}$, that constitute a fluorescence resonance energy transfer (FRET) system, the same authors reported on the use of GMP-based nanowires as light-harvesting material (FIG. 6C). Once assembled in the nanostructure, light $\left(\lambda_{\text {ex }}=450 \mathrm{~nm}\right)$ is absorbed by thioflavin $\mathrm{T}$, transmitted by FRET first to thiazole orange and then pyronin $\mathrm{Y}$ $\left(\lambda_{\mathrm{em}}=573 \mathrm{~nm}\right)$, generating a photocurrent that demonstrates the functional relevance of triple-dye-doped nanofibres as light-harvesting antennae ${ }^{72}$. The electronic properties of G-based suprastructures were further studied by Wasielewski and colleagues, who investigated the properties of guanines with electron-acceptor moieties such as perylene-3,4,9,10-bis(dicarboximide) (PDI) derivatives. The resulting GPDI self-assembles into octamers upon interaction with $\mathrm{K}^{+}$(FIG. 6a). Femtosecond transient absorption spectroscopy was used to demonstrate that $\left[(\mathrm{GPDI}) \mathrm{K}^{+}(\mathrm{GPDI})\right]$ undergoes efficient charge separation upon photoexcitation at $\lambda_{\mathrm{ex}}=525 \mathrm{~nm}$. The lifetime of the charge-separated intermediate in the octameric assembly was determined to be $1.2 \mathrm{~ns}$, as compared with 98 ps for the monomeric $\mathrm{GPDI}^{73}$. Using a dimeric system with two guanosines appended to the core perylene diimide, the same authors constructed SQ organic frameworks and showed their ultrafast production of long-lived mobile charges (radical ion pairs, or polarons) upon photoexcitation $\left(\lambda_{\text {ex }}=500 \mathrm{~nm}\right.$; FIG. $\left.6 \mathrm{~d}\right)$. The excellent electrical conductivity of these frameworks was exploited to assemble a SQ-based Li-ion battery, which proved to be robust $(<7 \%$ loss of efficiency after 300 charge/discharge cycles $)^{74}$.

G-quartets also served as a platform for interacting with small-molecule partners to endow the resulting G-quartet/ligand complex with specific properties. Two examples were discussed above: the interaction of thiazole orange with a c-di-GMP octamer (FIG. 4b), in which the resulting quadruplex/ligand complex is fluorescent (and, thus, detectable), and the interaction of TASQ with G4-ligands (FIG. 4c), which allows for quantifying in vitro the parameters that govern the ligand/ target interaction. Combining these two approaches, Sintim and colleagues developed a bioinspired catalytic system for the oxidation of 2,2'-azino-bis(3-ethylbenzothiazoline-6-sulfonic acid) (ABTS; FIG. 7). In the presence of an intercalator (proflavine), c-di-GMP forms a quadruplex that externally binds hemin (protoporphyrin IX iron(III) chloride ${ }^{75}$, a well-known cofactor of 


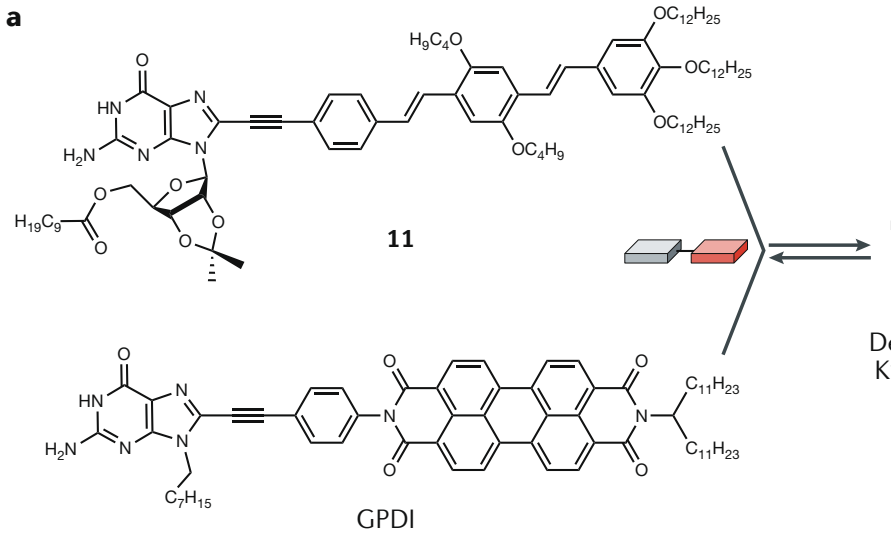

b

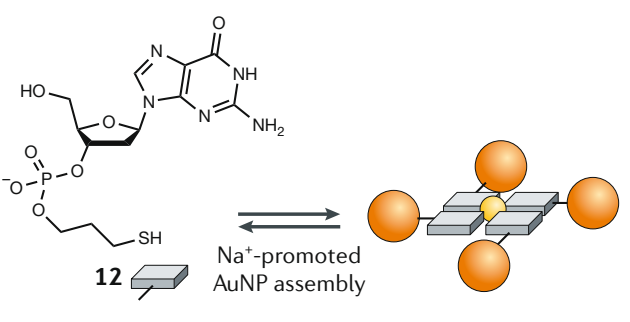

Decorated (OPV or PDI)

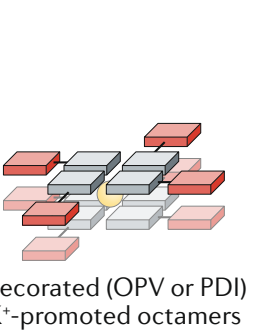

|FRET 2<smiles>Nc1nc2c(ncn2C2OC(COP(=O)([O-])O)C(O)C2O)c(=O)[nH]1</smiles>

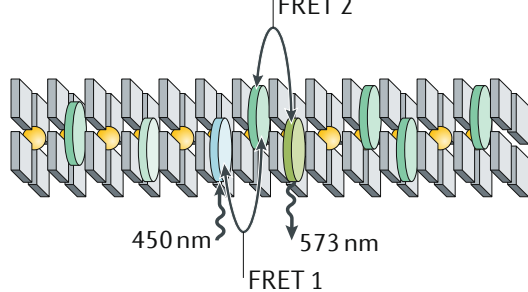<smiles>Cc1ccc2c(c1)sc(-c1ccc(N(C)C)cc1)[n+]2C</smiles><smiles>CN1C=C/C(=C\c2sc3ccccc3[n+]2C)c2ccccc21</smiles><smiles>CN(C)c1ccc2cc3ccc(=[N+](C)C)cc3cc2o1</smiles>
ThT $\rightleftharpoons$ $\mathrm{TO} \Leftarrow$ $P Y \rightleftharpoons$

d<smiles></smiles>

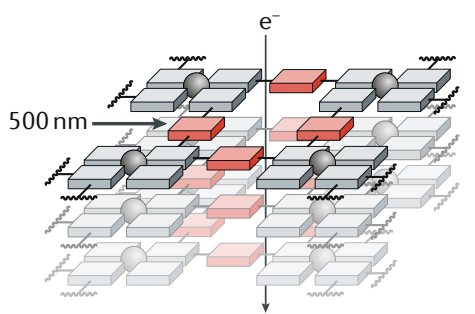

Fig. 6 | The nanotechnological applications of synthetic G-quartets-based nanostructures. a | Decorated lipophilic guanosines self-assemble into octamers with enhanced properties, i.e. enhanced fluorescence for $(\mathbf{1 1})^{45}$ and charge separation under photoexcitation for guanine perylene-3,4,9,10-bis(dicarboximide) (GPDI) ${ }^{73}$. b | Gold nanoparticle assembly triggers by $(\mathbf{1 2})^{69}$, which provides micrometre-long architectures with increased plasmon coupling. c| Guanosine monophosphate (GMP)-based nanowires that act as light-harvesting antenna upon association with fluorescence resonance energy transfer (FRET) dyes triplets ${ }^{72}$, i.e. thioflavin $\mathrm{T}$ (ThT), thiazole orange (TO) and pyronin Y (PY). d | G-quadruplex organic frameworks that produce long-lived mobile charges upon photoexcitation, making them prototypes of a G-quartet-based Li-ion battery ${ }^{74}$. OPV, oligo( $p$-phenylene vinylene); PDI, perylene-3,4,9,10-bis (dicarboximide); SQ, synthetic G-quartets.

hemoproteins, such as horseradish peroxidase (HRP), and a key biochemical tool in the development of the enzyme-linked immunosorbent assay (ELISA). The catalytic activity of G-quartet-containing biomolecules, i.e. quadruplex-DNA (G4-DNAzyme), was discovered during investigations that aimed to identify aptamers for catalysing porphyrin metalation. Aptamers with a high affinity for N-methyl mesoporphyrin IX (NMM) were investigated, given that NMM is a transition-state analogue for porphyrin metalation and a potent inhibitor of ferrochelatase, an enzyme that catalyses the insertion of iron into protoporphyrin IX (the last step of haem biosynthesis). Through systematic evolution of ligands by exponential enrichment (SELEX) experiments, Sen and colleague identified a short, 24-nt DNA referred to as PS5.M that strongly binds to NMM and catalyses the metalation of mesoporphyrin $\mathrm{IX}^{76,77}$. Importantly, it was shown that the catalytic activity of PS5.M is inhibited by hemin through the formation of a high-affinity PS5.M/hemin complex. This observation drove the authors to assess whether it could elicit hemoprotein-like properties, notably peroxidases. Upon addition of a stoichiometric oxidant (hydrogen peroxide, $\mathrm{H}_{2} \mathrm{O}_{2}$ ), the complex was found to accelerate 250 -fold the oxidation of the chromogenic substrate $\mathrm{ABTS}^{78}$. In light of the G-richness of PS5.M (d $\left[{ }^{5} \mathrm{GTG}_{3}\right.$ TCAT $_{2} \mathrm{GTG}_{3} \mathrm{TG}_{3}$ $\left.\mathrm{TGTG}_{2}{ }^{{ }^{\prime}}\right]$ ) and the $\mathrm{K}^{+}$-dependency of its catalytic activity, the authors wisely mused about its quadruplex structure $^{79}$, which offers a defined binding site to hemin that becomes catalytically competent once nestled within this site only. It is intriguing that, more than three decades after its discovery, the precise mechanism of quadruplex DNAzyme remains unclear ${ }^{80-82}$, despite hundreds of new applications reported each year (for relevant reviews, see $\mathrm{REFS}^{83-85}$ ). Inspired by Sintim's work, Spinelli and colleagues further exploited the intramolecular assembly of TASQ to provide versatile catalytic systems (TASQzyme) that could be applied with a variety of pre-catalysts, cofactors and substrates ${ }^{86}$. Monchaud and colleagues used the non-anionic TASQ (e.g. DOTASQ; FIG. 7) (in place of anionic DNA or c-di-GMP) to replace the poorly soluble hemin cofactor with the more practically 

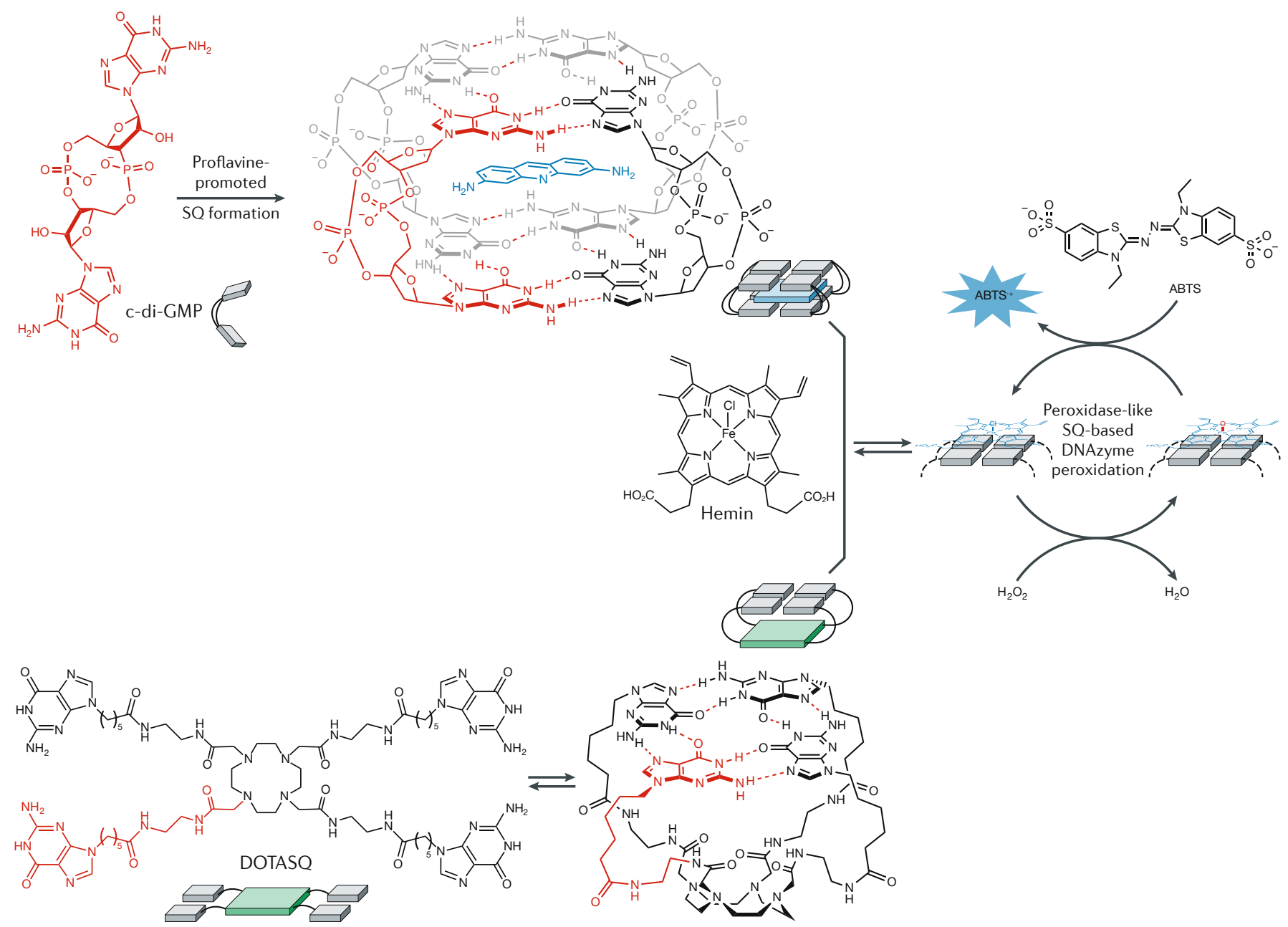

Fig. 7 | DNAzyme-type catalysis performed by G-quartet molecular tools. Catalytic guanosine (G)-quartets comprising either proflavine-promoted c-di-GMP octamer ${ }^{75}$ or the intramolecularly folded DOTASQ ${ }^{87}$ upon interaction with hemin, which makes the resulting G-quartet/hemin complex catalytically competent to oxidize the chromogenic 2,2'-azino-bis(3-ethylbenzothiazoline-6-sulfonic acid) (ABTS) in the presence of $\mathrm{H}_{2} \mathrm{O}_{2}$ (as the stoichiometric oxidant), in a DNAzyme-type manner ${ }^{85}$. SQ, synthetic G-quartets.

\section{Logic gates}

in electronics, a logic gate is a device that performs a logical operation on one or two inputs and produces a single output. Logic gates are primarily implemented as switches of different possible natures (AND, OR, NOT, INHIBIT etc.) in digital circuits. convenient 5,10,15,20-tetrakis(4-sulfonatophenyl) porphyrinato iron (III) chloride (FeTPPS) ${ }^{87}$. The construction of catalytic G-quartets is, however, not limited to assembly from G-dimers and G-tetramers: recently, Davis and colleague showed that GMP itself could assemble to form an efficient thermosensitive catalyst for DNAzyme-like reactions, offering higher catalytic rates at low temperature, owing to an improved stability of GMP-based G-quadruplex structure at $10^{\circ} \mathrm{C}$ versus $30^{\circ} \mathrm{C}\left(\mathrm{REF}^{88}\right)$. Dash and colleagues reported on the design of catalytic G-quartet-based hydrogels formed by boronate-ester-functionalized guanosines that act as logic gates. $\mathrm{K}^{+}$and $\mathrm{Pb}^{2+}$ are the on and off inputs, respectively, and the product of the oxidation of $3,3^{\prime}, 5,5^{\prime}$-tetramethylbenzidine is the output, thanks to its characteristic absorbance signal at $652 \mathrm{~nm}$ that provides a convenient readout of the efficiency of the operation ${ }^{89}$. Pei and colleagues exploited a similar approach to design bioelectronics nanodevices (i.e. an electrochemical glucose sensor based on the concerted action of glucose oxidase and hemin-mediated catalytic G-quartets embedded in a hydrogel matrix $)^{90}$.

\section{G-quartet-based soft matter}

Soft matter refers to materials whose properties occupy the tenuous frontier between the solid and liquid states. The study of soft matter was popularized by de Gennes, whose work was recognized by the award of the Nobel Prize in Physics 1991 (REF. ${ }^{91}$ ). These materials have low elastic moduli, enabling them to withstand thermal fluctuations and external deformations, thanks to internal structural rearrangements that allow for energy dissipation in response to external stress ${ }^{92}$. They can be produced from a variety of organic and inorganic molecular entities (e.g. clay, metal oxides, synthetic and natural polymers and proteins) and encompass a wide diversity of systems, including colloid suspensions, emulsions, foams, surfactants, liquid crystals or gels.

The pioneering works on the ability of GMP to form hydrogels ${ }^{7,8,10}$ cast a bright light on G-quartets as soft-matter building blocks ${ }^{93}$. For example, Gottarelli et al. studied the formation of columnar aggregates by the lipophilic $3^{\prime}, 5^{\prime}$-didecanoyl-2' -deoxyguanosine (2) $)^{94,95}$ and sought to characterize them both structurally and stereochemically. They noticed that 
a

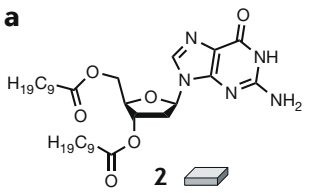

b<smiles>CC1(C)OC2(COC(=O)CCC(=O)NC34CC5CC(CC(C5)C3)C4)OC(n3cnc4c(=O)[nH]c(N)nc43)(O1)O2</smiles>
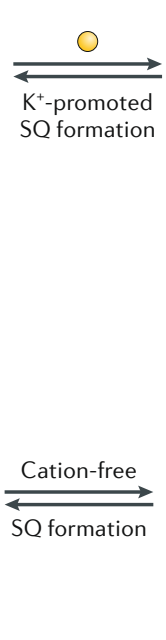
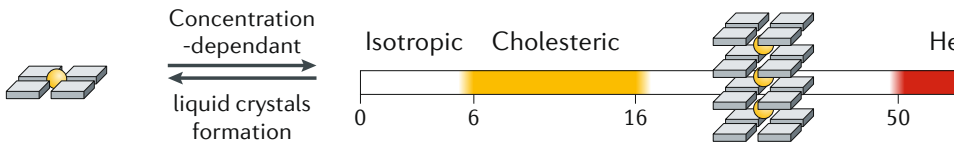

Hexagonal

50

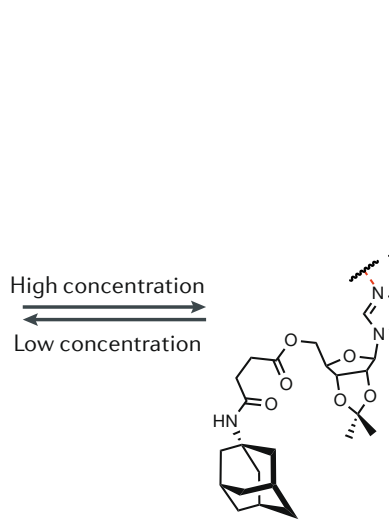

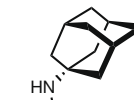

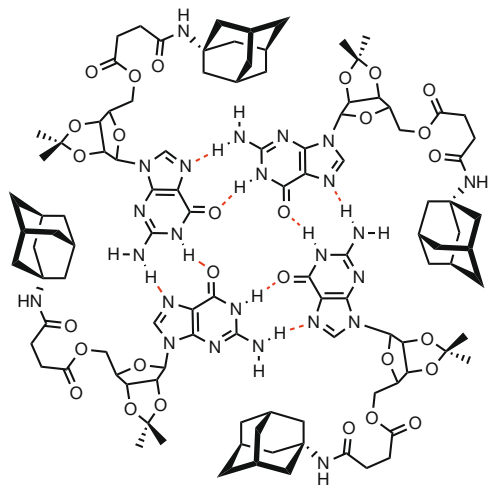

Liquid state

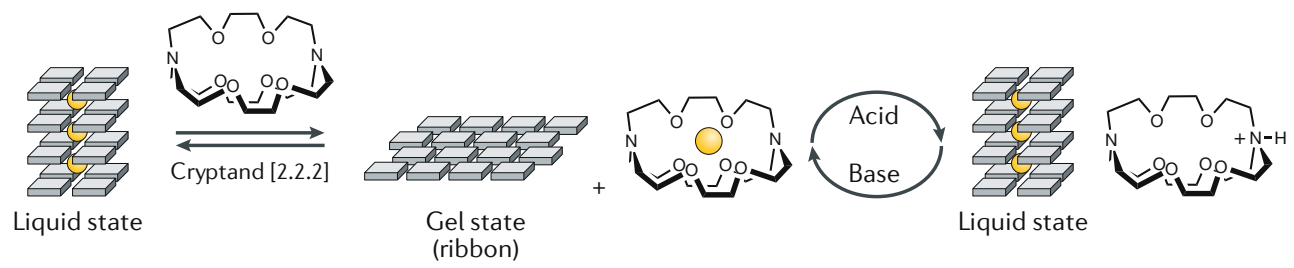

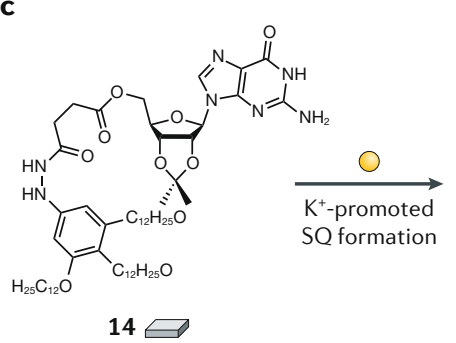

(ribbon)

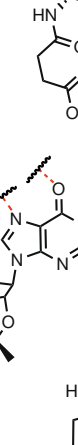

上。<smiles>O=CC12COC1CO2</smiles>
$60[(2)] w / w$

d

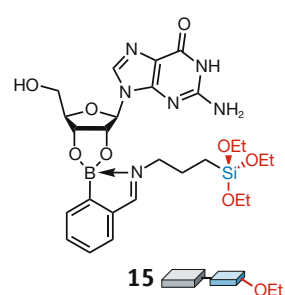

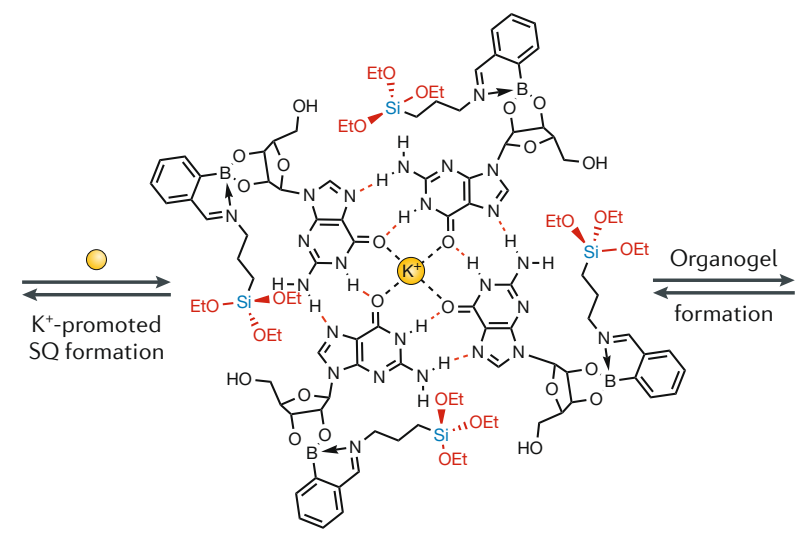

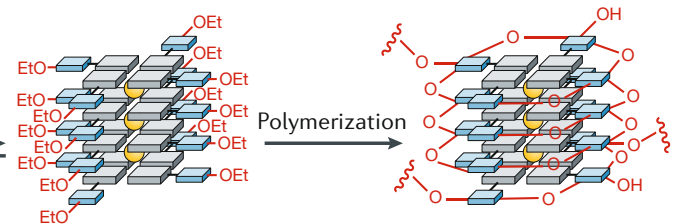

Fig. 8 | Soft matter based on G-quartet molecular devices. a |Amphiphilic guanosine (G; 2) that self-assembles into a lyotropic liquid crystal triggered by a $\mathrm{K}^{+}$-promoted synthetic G-quartets (SQ) formation ${ }^{96}$. b $\mid$ Cation-free SQ formed by adamantyl-conjugated guanines $(\mathbf{1 3})^{99}$, whose $\mathrm{SQ} /$ ribbon topological transition is controlled by the concentration. c| Dynamic hydrogel (or dynamers) formed by hydrazide-based guanines (14) ${ }^{100}$ and controlled by cryptand [2.2.2] and sequential acid/base addition. $\mathbf{d}$ | Water-assisted polymerization of siloxane-conjugated guanines (15) ${ }^{103}$ to form covalent crystalline nanorods.

lyotropic liquid crystal phases were formed in heptane in the presence of potassium picrates ${ }^{96}$. At high dilution $(<6 \% \mathrm{w} / \mathrm{w})$, an isotropic phase was observed, while medium $(6-16 \% \mathrm{w} / \mathrm{w})$ and high $(40-50 \% \mathrm{w} / \mathrm{w})$ concentrations led to a left-handed cholesteric phase and a hexagonal phase, respectively (FIG. 8a). X-ray measurements confirmed the columnar nature of the G-quartet-based self-assemblies with characteristic peaks at $3.4 \AA$ corresponding to the stacking of G-quartets and an additional calculated radius of $12 \AA$ for the hexagonal phase, fitting with the G-quartet radius. However, in ion-free conditions, $\mathbf{2}$ and other LipoG derivatives also exhibit lyotropic properties in both toluene and chloroform, in this case due to the formation of G-ribbons ${ }^{97}$. Recently, Kato and colleagues reported on thermotropic liquid-crystal formation with C8-oligothiophene guanine derivatives. In this case, both the nature of the phases and the phase transitions were modulated by potassium ion concentration. As well as the hexagonal columnar phases based on G-quartet assemblies (as already reported for 2), 
Storage moduli

indications of the ability of the gel to withstand and store deformation energy in an elastic manner, being dependent on its crosslinking state

Thixotropy property of a material (gel, fluid), which is thick or viscous under static conditions, to become thin and liquid when shaken or sheared.
G-ribbon formation leads to bicontinuous cubic phase rarely observed for $\pi$-conjugated liquid crystals ${ }^{98}$. G-quartets have also been used to formulate organogels and hydrogels, assembled in organic solvents or aqueous media, respectively. As an example, Yi and colleagues demonstrated that $5^{\prime}$-(adamantylcarbamoyl)propionate-2', $3^{\prime}$-isopropylidene-guanosine (13) can form an organogel even in the absence of cations when working above the critical gelation concentration $(>50 \mathrm{mM})$. The sol-gel transition results from a structural change from G-quartets (assembled at low concentration, $<10 \mathrm{mM}$ ) to type A G-ribbons (FIG. 8b). Gelation occurred when ribbons self-assembled into micrometre-width hexagonal columnar structures; a morphological change can be triggered by ultrasonication, which favours twisted-flower-like structures ${ }^{99}$. Liu and colleagues observed a similar behaviour with a guanine functionalized with a 3,4,5-tris ( $n$-dodecan-1-yloxy)benzohydrazide (14): the quartet-to-ribbon structural transition was solvent-dependent, occurring above $17 \% \mathrm{w} / \mathrm{w}$ in toluene and above $29 \% \mathrm{w} / \mathrm{w}$ in chloroform. This transition was harnessed to build a dynamic organogel. In the presence of cryptand [2.2.2], which is known to chelate $\mathrm{K}^{+}$ions, sequential additions of trifluoroacetic acid and triethylamine trigger switching between the G-quartet formation (sol state) in the presence of base and the G-ribbon formation (gel state) in the presence of acid $^{100}$ (FIG. 8c). The strategy of using cryptands to modulate G-ribbon/G-quartet interconversion was previously described in organic solution by Spada and colleagues with LipoG (2) ${ }^{101}$ and a 5'-O-oligothiophene guanine derivative ${ }^{102}$. Higher-order, self-organized, hybrid organic/inorganic materials have also been built on G-quartet-based organogels formulated from a guanine-siloxane derivative (15) in the presence of $\mathrm{K}^{+}$or barium $\left(\mathrm{Ba}^{2+}\right)$ ions ${ }^{103}$. The polymerization of $\mathrm{SiR}_{2}-\mathrm{OEt}$ into $-\mathrm{SiR}_{2}-\mathrm{O}-\mathrm{SiR}_{2}-$ was triggered by water, leading to higher-ordered hybrid materials with micrometric crystalline-rod morphologies (FIG. 8d). Similarly, self-organized organic polymers that exhibit microfibre or microspring morphologies can be accessed from a $5^{\prime}$-O-methacrylate guanosine derivative, with the morphology switching dependent on cationdriven G-ribbon or G-quadruplex adopted assembly, respectively ${ }^{104}$.

The majority of G-quartet-based soft matter described to date focuses on the formation of hydrogels. From the initial pioneering observations of the GMP gelation process ${ }^{7,8,10}$, a vast amount of research has been conducted in order to decipher the parameters that govern the formation of hydrogels and improve the scope of their applications. GMP-based gels have mostly been formulated with monovalent or divalent cations (see above); however, the use of trivalent lanthanide ions, including lanthanum $\left(\mathrm{La}^{3+}\right)$, cerium $\left(\mathrm{Ce}^{3+}\right)$, europium $\left(\mathrm{Eu}^{3+}\right)$ and terbium $\left(\mathrm{Tb}^{3+}\right)$, led to SQ-based nanofibrillar networks in acidic conditions ${ }^{105}$. As a result of its high aqueous solubility, GMP alone does not form a gel at neutral $\mathrm{pH}$. However, upon addition of phosphate-free guanosines, gelation occurs and the modulation of the GMP/guanosine ratio can be used to fine-tune the resulting material properties ${ }^{106,107}$.
These gels exhibit unusual thermoassociative behaviour, with the sol-gel transition taking place above a specific temperature ${ }^{108}$. In the presence of different monovalent cations (from $\mathrm{Li}^{+}$to $\mathrm{Cs}^{+}$), guanosine alone can also form a hydrogel, but it is stable for only a few minutes or hours. This instability can be addressed by the addition of 0.7-1.5 molar equivalents of lipophilic $2^{\prime}, 3^{\prime}, 5^{\prime}$-tri- $O$-acetylguanine (16), which enhances the gel lifetime from hours to years and also increases the sol-gel transition temperature (from $50^{\circ} \mathrm{C}$ to $>60^{\circ} \mathrm{C}$ ) ${ }^{109}$ (FIG. 9a). Another possibility is to formulate the gel with metal ions such as silver $\left(\mathrm{Ag}^{+}\right)$, which increases the stability (from hours to months) and the storage moduli (up to $8 \mathrm{kPa}$ ) and endows the resulting gel with thixotropy ${ }^{110}$. Addition of isoguanosine is another alternative to turn guanosine gels into thixotropic co-gels exhibiting very short recovery times $(<20 \mathrm{~s})^{111}$.

Davis and colleagues thoroughly exploited guanosine-borate assemblies ${ }^{112}$, which showed high propensity to form stable hydrogels (with storage moduli $>10 \mathrm{kPa}$ at $0.2 \mathrm{wt} \%$; FIG. 9b). These gels have been used to incorporate a wide variety of chemicals, notably fluorescent dyes. Even at extremely low concentration $\left(2.5 \times 10^{-3}\right.$ molar equivalents), these probes impact the hydrogel properties - decreasing gel stiffness in the case of, e.g. rhodamine $\mathrm{B}$ and Rose Bengal, or increasing it in the presence of, e.g. thioflavin $\mathrm{T}$ or thiazole orange ${ }^{113}$. Guanosine-borate systems were also used in the preparation of photoreversible hydrogels, in which the photoswitch $E-4,4^{\prime}$ dioxyethylpiperidinium iodide-azobenzene controls the G-quartet-based assembly $\left(\lambda_{\mathrm{ex}}=436 \mathrm{~nm}\right)$ and disassembly $\left(\lambda_{\mathrm{ex}}=365 \mathrm{~nm}\right)^{114}$. Lehn and colleague developed smart, G-quartet-based hydrogels, using water-soluble G-dimer (17). As above, the sol-gel equilibrium of these $\mathrm{K}^{+}$-promoted dynamic polymers can be fully controlled by sequential addition of cryptand [2.2.2] and $\mathrm{HCl}$ to control the availability of $\mathrm{K}^{+}$to promote $\mathrm{G}$-quartet formation $^{115}$. Another dynamer was developed to exploit the reactivity of monomeric guanosine- $5^{\prime}$-hydrazide (18) with a library of aldehydes, in order to assemble acylhydrazone-based hydrogels capable of dynamically self-selecting the most stable gel under the experimental conditions $^{116-118}$ (FIG. 9c). Barboiu and colleagues reported a double-dynamer system based on the reversible reaction between guanosines and a bisiminoboronic acid linker to form bisiminoboronate-G-dimers, whose equilibrium between the cation-free ribbon state and $\mathrm{K}^{+}$-promoted G-quartet state led to the production of two types of functional membrane films ${ }^{119}$.

Interesting biotechnological and biological applications have been reported with G-quartet-based hydrogels. Dash et al. used $\mathrm{Ag}^{+}$to formulate hydrogels that enable the incorporation of cytochrome $c$ into GMP-based gels ${ }^{120}$. Zhao and colleagues described the preparation of an antimicrobial hydrogel (active against Gram-negative bacteria) by incorporating $2^{\prime}$-deoxy-2' fluoroguanosine (19) ${ }^{121}$ (FIG. 9a). The controlled release of bioactive compounds from G-quartet-based hydrogels has been described as a method for drug delivery. For example, the release of vitamin $\mathrm{C}$ and the $\mathrm{G}$-containing drugs acyclovir and ganciclovir has been achieved using hydrogels based on guanosine- $5^{\prime}$-hydrazide ${ }^{122}$, 
a<smiles>CC(=O)OCC1OC(n2cnc3c(=O)[nH]c(N)nc32)C(OC(C)=O)C1OC(C)=O</smiles><smiles>CNc1nc(N)[nH]c(=O)c1N</smiles><smiles>Cc1cn(CC(=O)NCCOCCOC(C)(C)CNC=O)cn1</smiles>

17<smiles>NNC(=O)Cn1cnc2c(=O)[nH]c(N)nc21</smiles><smiles>[Z16]C(=O)OC1OC(COC(C)=O)(OC(C)=O)C1n1c(OC)nc2c(=O)[nH]c(N)nc21</smiles>

b

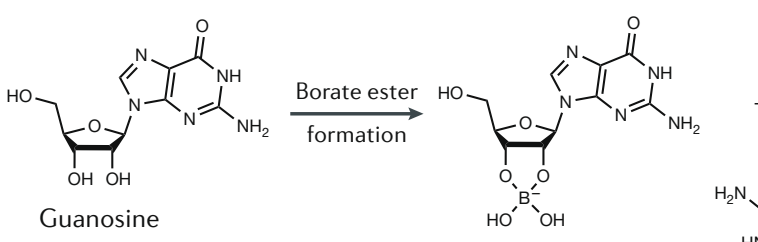

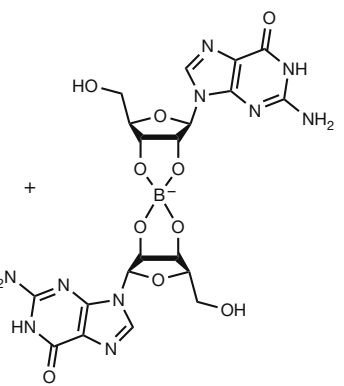

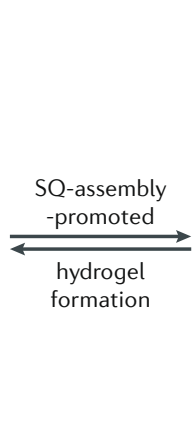

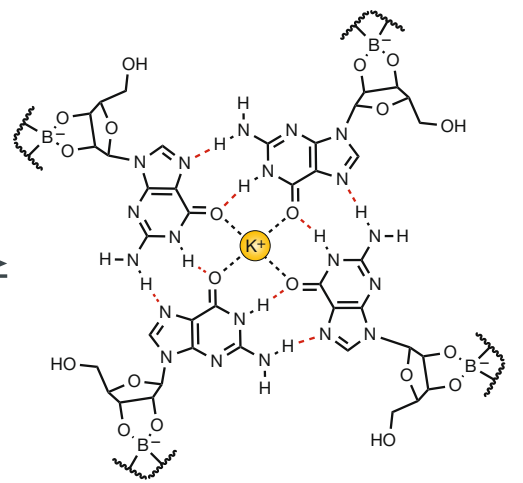

c<smiles>NNC(=O)C1OCC2(O1)OC2n1cnc2c(=O)[nH]c(N)nc21</smiles>

$182_{\mathrm{NHNH}_{2}}$

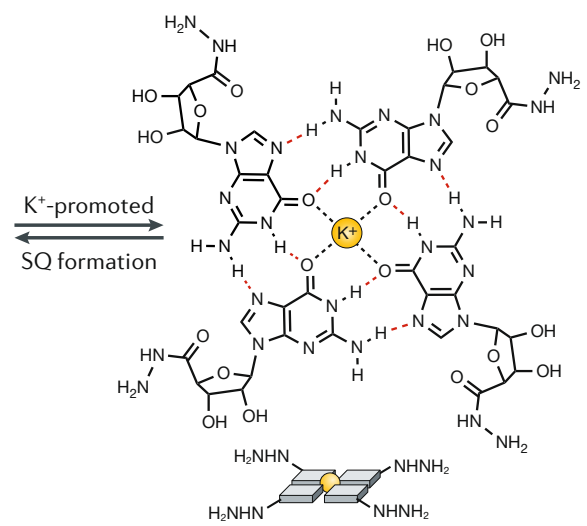

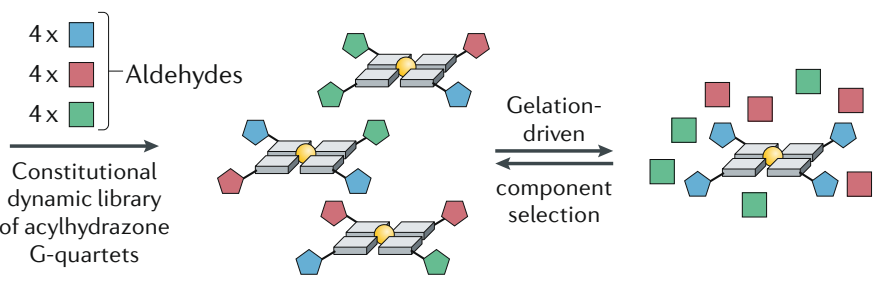<smiles>[Z]#CC(C)(C)OCn1cnc2c(=O)[nH]c(N)nc21</smiles>

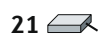<smiles>Nc1nc2c(ncn2C2OC(CO)(CO)C(O)C2O)c(=O)[nH]1</smiles>

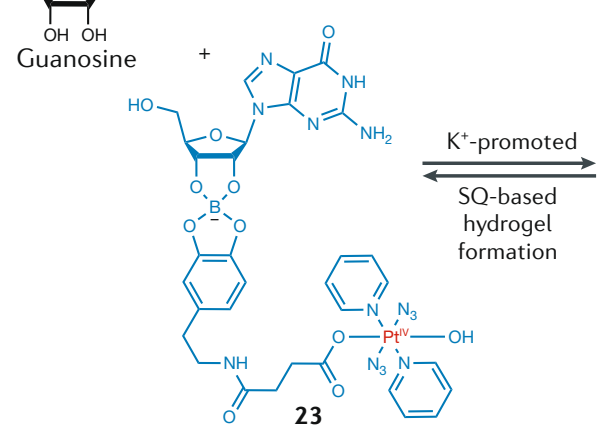

$\underset{\text { SQ formation }}{\stackrel{\substack{\mathrm{K}^{+} \text {and boric acid } \\ \text {-promoted }}}{\rightleftarrows}}$

$$
\text { Acyclovir }
$$$$
\text { The for }
$$

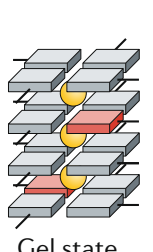

Gel state
Intramolecular cyclization of

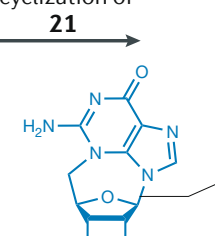
$22 \mathrm{OH} \mathrm{OH}$
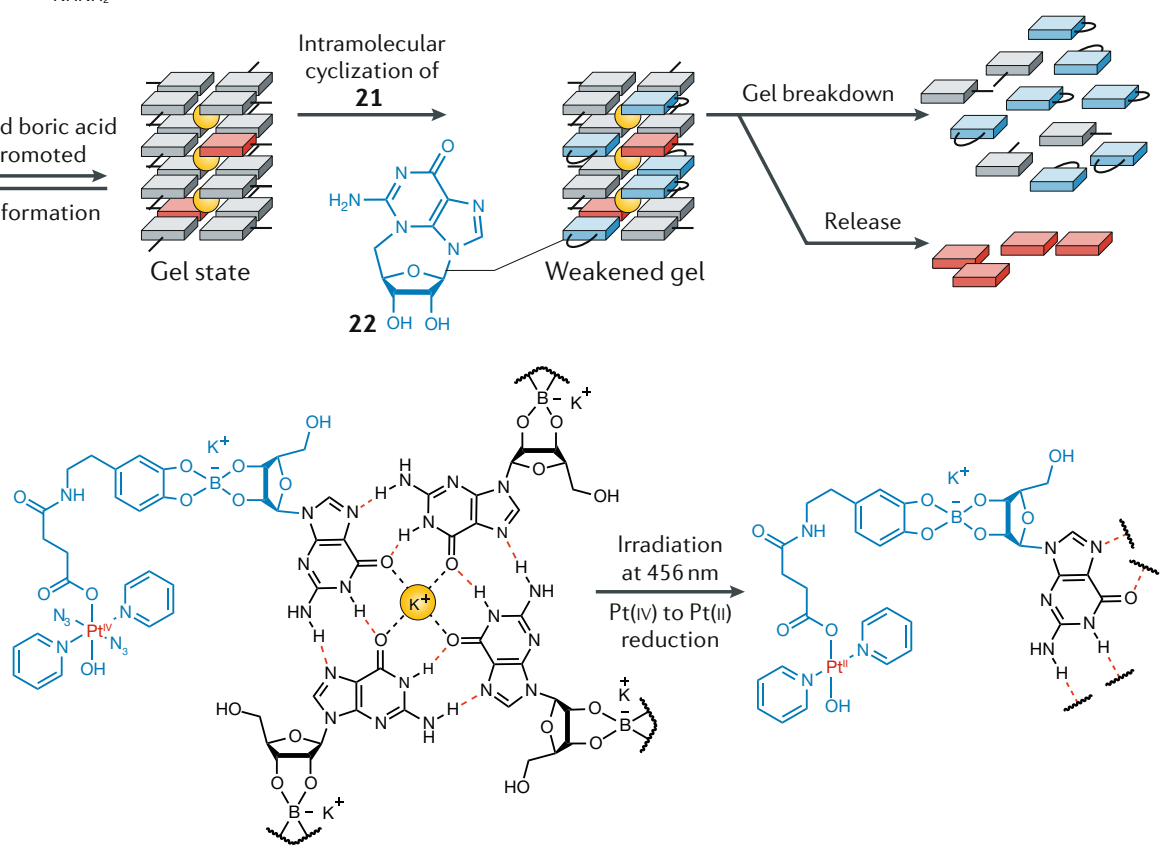

Fig. 9 | Supramolecular hydrogels based on G-quartet assemblies. a | Guanine derivatives (16) $)^{109},(\mathbf{1 7})^{115},(\mathbf{1 9})^{121}$, (20) ${ }^{123}$ and (24) ${ }^{126}$ used as building blocks for hydrogels. b | Guanosine-borate-based hydrogels used for incorporating a wide variety of chemicals ${ }^{112}$. c| Dynamic self-selection of aldehydes from (18) that provides the most stable gel ${ }^{118}$. d | Following gel formation, the cyclization of (21) to (22) triggers gel weakening and collapse, allowing the controlled release of acyclovir incorporated into the stacked guanosine (G)-quartet assemblies ${ }^{124}$. e | Biological application of a platinum-G-quartet-based hydrogel exhibiting photoactivatable anticancer properties ${ }^{125}$. 
guanosine/bromoguanosine (20) (1/1) mixture ${ }^{123}$ or $5^{\prime}$-deoxy-5'-iodoguanosine (21 $)^{124}$. In the latter case, an intramolecular cyclization that forms $5^{\prime}$-deoxy-N3, $5^{\prime}$-cycloguanosine (22) leads to gel breakdown, triggering the release of acyclovir ( $>80 \%$ release after 3 days) that had previously been incorporated into the stacked G-quartet assemblies through its guanine moiety (FIG. 9d). Sadler and colleagues further exploited this approach, incorporating a guanosine-borate $\mathrm{Pt}(\mathrm{IV})$ complex (23) into a guanosine-borate hydrogel to exploit the photo-activatable anticancer properties of platinum ${ }^{125}$. Under visible-light irradiation $\left(\lambda_{\mathrm{ex}}=465 \mathrm{~nm}\right)$, the photoreduction of $\mathrm{Pt}(\mathrm{IV})$ to cytotoxic $\mathrm{Pt}(\mathrm{II})$ combined with the release of azidyl radicals (FIG. 9e) triggers higher cytotoxicity in cisplatin-resistant A2780cis human ovarian cancer cells $\left(\mathrm{IC}_{50}=3 \mu \mathrm{M}\right)$ than cisplatin and chlorpromazine ( $\mathrm{IC}_{50}>100 \mu \mathrm{M}$ and $6 \mu \mathrm{M}$, respectively), with a better selectivity towards normal MRC- 5 human fibroblast cells $\left(\mathrm{IC}_{50}>50 \mu \mathrm{M}\right)$.

Rowan and colleagues described the application of hydrogels derived from 8-methoxy-2', 3', $5^{\prime}$-tri- $O$-acetylguanosine (24) as a scaffold for tissue engineering. C166 endothelial cells were incubated in cell culture medium DMEM/24 mixtures (between $0 \mathrm{wt} \%$ and $2 \mathrm{wt} \%$ ), the addition of gelatin ( $1 \mathrm{wt} \%)$ providing a tridimensional co-gel within which cells can be incorporated, as observed by confocal microscopy ${ }^{126}$. The choice of benzene-1,4-boronic acid instead of simple boronic acid to form a guanosine-borate hydrogel provides an efficient support for human dermal fibroblast growth with cell viability $>73 \%$ when formulated with both $\mathrm{K}^{+}$ (triggering the G-quartet formation) and magnesium (crosslinking the anionic borate moieties ions) ${ }^{127}$. Altogether, these studies confirm the versatility of G-quartet-based soft matter and highlight their high potential as biomaterials.

\section{Applications in chemical biology}

As it may have become apparent from the discussion above, increased understanding and popularity of G-quartets as supramolecular building blocks has also increased our understanding of these structures in their natural setting - within DNA and RNA quadruplexes. The prevalence of G4s in the human genome, transcriptome and ncRNAome (G4ome) is now firmly demonstrated thanks to the recent and spectacular development of sequencing technologies ${ }^{128}$ (FIG. 1): G4-seq identified $>716,000$ potential DNA quadruplex-forming sequences (QFS) in the human genome ${ }^{129}$ and G4 ChIP-seq decreased this number to $10,000 \mathrm{G} 4$ sites, because of the topological restriction imposed by the chromatin environment $^{130}$; rG4-seq identified $>13,000$ QFS in the human transcriptome (polyA-enriched RNA) ${ }^{131}$, while G4RP-seq extended the analysis to the whole transcriptome and ncRNAome, demonstrating that G4s are pervasive structures in functional human cells ${ }^{132}$. Therefore, the prevalence of G4s and their established functional relevance ${ }^{16,17}$ have made them new stars in genetics and promising targets for therapeutic interventions. Specially dedicated G4-ligands ${ }^{133-135}$, such as quarfloxin ${ }^{136}$, BRACO-19 (REF. ${ }^{137}$ ), PhenDC ${ }^{138}$ and pyridostatin ${ }^{139}$, were developed in the hope of gaining control over the many cellular processes in which G4s are involved. Most, if not all, programmes that have attempted to identify promising new G4-ligands have chemical scaffolds primarily developed as duplex DNA intercalators (acridine, quinoline, etc.). This approach is somewhat surprising, given that binding to duplex DNA is the major unwanted interaction that would need to be avoided for a G4-ligand to be considered promising. That said, successful strategies have been devised that avoid duplex interaction, such as using ligands with large to very large aromatic cores to maximize overlap with the external G-quartet of a G4 structure and avoid duplex intercalation. Another approach that has emerged - as a result of the many structural studies on quadruplexes - is the use of synthetic G-quartets as bioinspired G4-ligands. This approach builds on the observation that the stability of quadruplex structures is frequently related to the number of constitutive G-quartets, and there is a like-likes-like recognition between natural and synthetic G-quartets (FIG. 10).

In order to circumvent the challenging kinetics associated with the assembly of four isolated guanines, the first biomimetic ligands developed were tetrameric TASQ, such as the neutral DOTASQ ${ }^{140,141}$ (FIG. 7). Further work led to the development of the first smart quadruplex ligands, which assemble only in the presence of their native G-quadruplex targets, for example, the cationic ${ }^{\text {PNA }}$ DOTASQ ${ }^{142,143}$ (FIG. 10a). PyroTASQ has been described as a 'twice-as-smart' quadruplex ligand ${ }^{144,145}$ (FIG. 10a), referring to the fact that it is both a smart quadruplex ligand and a smart, turn-on fluorescent probe. The exquisite selectivity of these ligands for their targets is a result of a unique G4-triggered intramolecular rearrangement of the ligand. TASQ ligands have been instrumental in the detection and identification of DNA/RNA quadruplexes in human cells using optical imaging (for example, N-TASQ was used as a probe to directly visualize DNA/RNA quadruplexes in human cells; FIG. 10a,b $)^{146,147}$ and sequencing studies (BioTASQ was used for the pull down of RNA quadruplexes containing sequences from living human cells, enabling their identification through to the G4RP-seq protocol (G4-RNA-specific precipitation followed by sequencing); FIG. 10a,C) $)^{132,148}$. Together, these studies have both confirmed the existence of quadruplexes in functional human cells and provided tools to assess the ligand-induced changes in the quadruplex landscape upon therapeutic treatments.

Intermolecular SQ have also been used as biomimetic ligands. Rivera and colleagues reported on the use of quartets self-assembled from the 8-aryl-2' deoxyguanosine derivative (25) and showed that this cationic guanine spontaneously folds into $\mathrm{K}^{+}$-promoted or $\mathrm{Na}^{+}$-promoted hexadecamers, which are subsequently sandwiched between two quadruplex units $\left[\mathrm{G} 4\left((\mathbf{2 5})_{4} \mathrm{~K}^{+}(\mathbf{2 5})_{4} \mathrm{~K}^{+}(\mathbf{2 5})_{4} \mathrm{~K}^{+}(\mathbf{2 5})_{4}\right) \mathrm{G} 4\right]^{149}$ (FIG. 10d). These unusual, nanometre-long structures, whose stability is a result of extended networks of $\pi$-stacking and Coulombic interactions, describe a new possible G4-ligand/quadruplex binding mode and make 25 SQ the first example of a biomimetic, self-assembled ligand. Dash and colleagues also reported on the use of G-monomers and G-dimers 
<smiles>[R]NCCNC(=O)CN1CCN(CC(=O)NCCN[R])CCN(CC(=O)NCCN[R])C([R7])CN(CC(=O)NCCN[R])CC1</smiles><smiles>CC(C)CNC(=O)CCCCC1SCC2NC(=O)NC21</smiles><smiles>[R][CH]C(=O)CN(CCN)C(=O)Cn1cnc2c(=O)[nH]c(N)nc21</smiles><smiles>NCC#Cc1cc(C#CCN)c2ccc(C#CCN)c3cc(C#CCN)c4ccc1-c4c23</smiles>

PyroTASQ<smiles>[R]NCC#Cc1cc2cc(C#CCN[R])c(C#CCN[2H])cc2cc1C#CCN[R]</smiles>

N-TASQ b
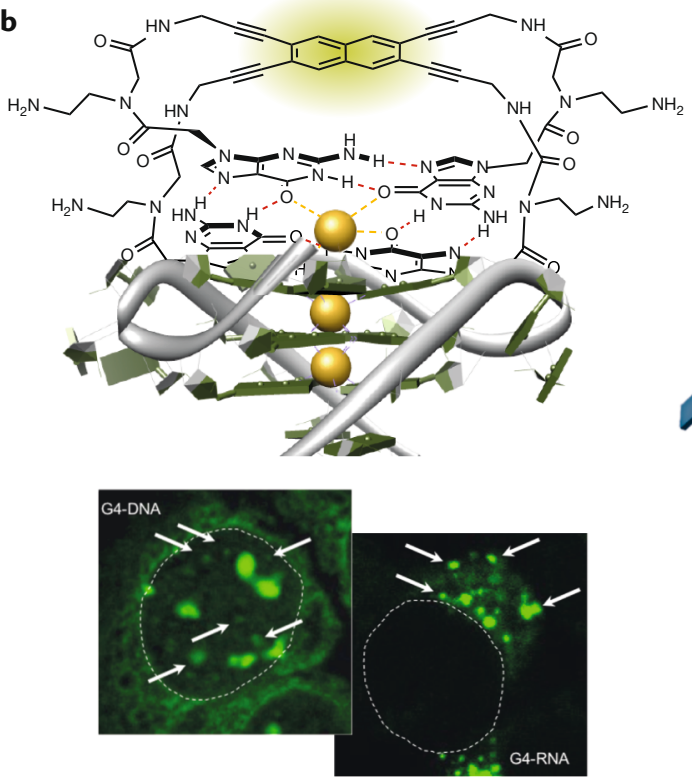

c

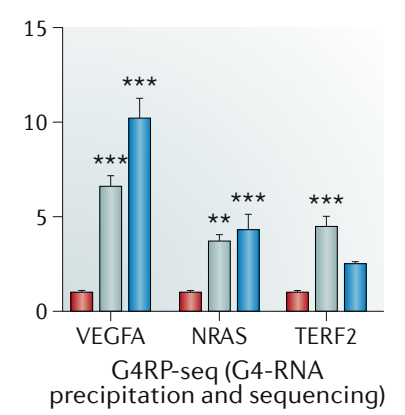

d

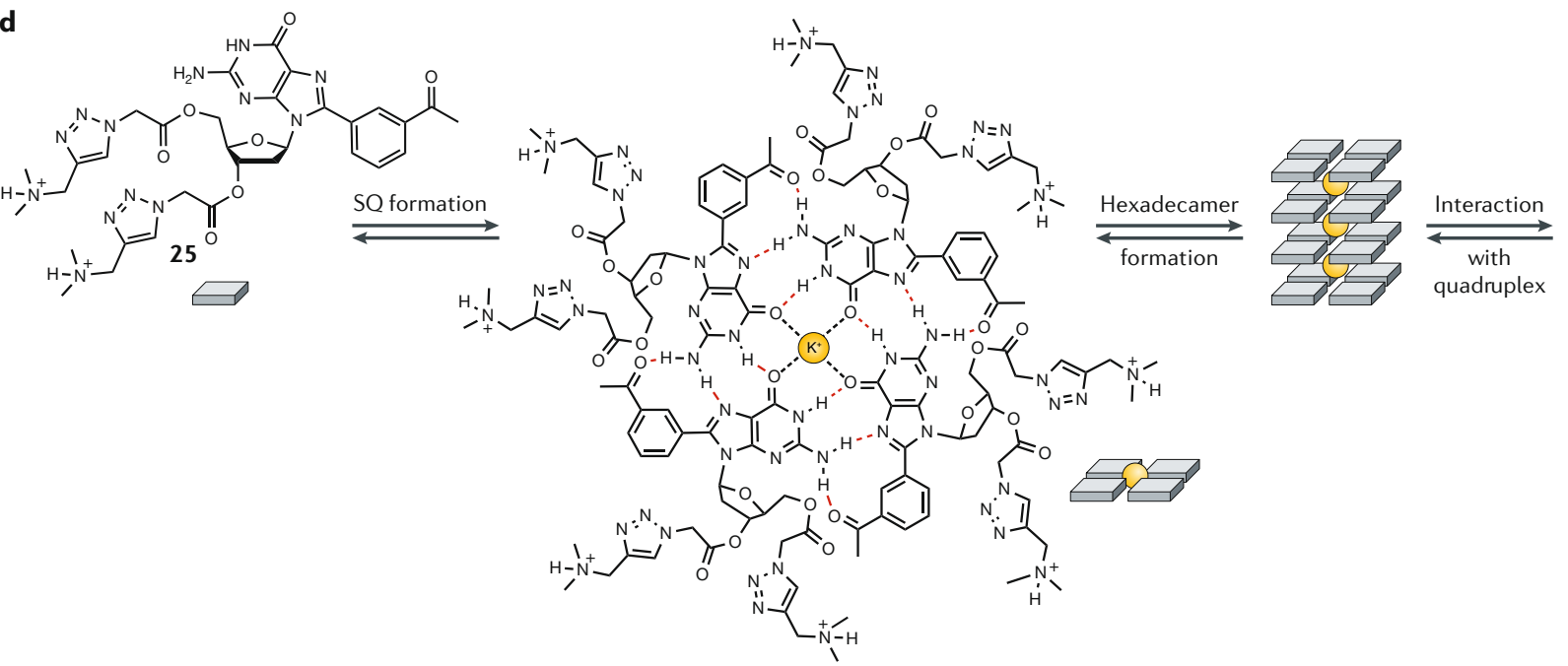

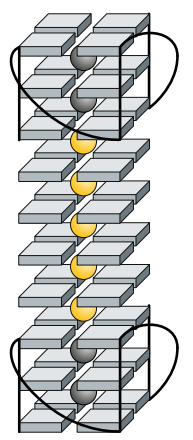

Fig. 10 | The chemical biology applications of SQ. a | Chemical structure of several template-assembled synthetic guanosine (G)-quartets (TASQ) used as biomimetic G-quadruplex ligands, i.e. ${ }^{\text {PNADOTASQ }}{ }^{142}$ and PyroTASQ ${ }^{144}, \mathrm{~N}^{-T A S Q}{ }^{146,147}$ and BioTASQ ${ }^{132,148}$. b | Schematic representation of the detection of quadruplexes in human cells using the twice-as-smart N-TASQ ligand. $\mathbf{c}$ Schematic representation of the use of BioTASQ as molecular bait to fish quadruplexes out of human cells prior to being identified by sequencing (G4RP protocol). ${ }^{* \star}$ and ${ }^{* * *}$ represent the statistical analysis (T test) of the results, $p$-values (with ${ }^{\star \star} p<0.01$ and $\left.{ }^{* \star *} p<0.001\right)^{132}$. d | Self-assembled G4-ligand resulting from the multimerization of $\mathbf{( 2 5})^{149}$ that is subsequently sandwiched between two quadruplex units. 
(dansyl monoguanosine and dansyl diguanosine) as G-quadruplex-interacting agents ${ }^{150}$. It is thought that these agents are groove binders (rather than themselves forming a quartet structure), but they were found to interact efficiently with the quadruplex found in the promoter region of the Myc oncogene (a gold-standard target for anticancer strategies) and capable of downregulating its expression in cancer cells.

\section{Conclusions}

Guanine was, is and will remain a fascinating study subject and likely has many functionalities that are yet to be discovered. Described above are just some of the applications that have been developed in the past two decades, and highlight an apparent disconnect between the simplicity of the guanine chemical scaffold and the diversity of fields in which guanines and their derivatives provide practical solutions. The careful selection of derivatives (guanine itself, guanosine, deoxyguanosine, GMP, etc.), combined with suitable chemical modifications, has enabled the assembly of a toolbox that appears to be virtually unlimited. Chemical modifications mean that guanine is useful in a variety of experimental conditions (organic or aqueous environments) and responsive to external stimuli (cation, $\mathrm{pH}$, light and temperature), which translates into programmable supramolecular properties. However, it is also immediately apparent that we are only beginning to assess the functional diversity of guanine in its entirety and to harness its supramolecular properties in a fully controllable manner.

To move up a gear, we believe that this field will have to shortly meet the following milestones.

Better predictions. Efforts must be invested to design G-based systems that will strictly obey predefined rules in terms of topological pluralism and stability. We need to understand and harness these rules with the help of in silico models to predict and encode the properties of G-based devices in the very structure of their basic guanine units.

Improved chemical strategies. The commercial accessibility of guanine derivatives sustains the use of G-based molecular tools in various research fields. However, the many examples discussed above highlight that only exquisitely tailored guanines provide devices with controllable properties. The relevance of a G-based molecular toolbox is, to date, far too dependent on high-tech chemistry. This might prevent academia-to-industry transitions in the short term.

Alternative chemical approaches. The supramolecular nature of this field of research must be further exploited, notably through alternative chemical strategies, such as dynamic combinatorial chemistry. This approach will undoubtedly offer alternative solutions to technical conundrums and improve the modularity and diversity of G-based devices.

New fields of applications. Beyond the aforementioned examples, more applications might benefit from G-based materials, from personalized medicine (for example, the use of G-rich aptamers as therapeutics) to climate-change issues (for example, G-polymers harnessing solar energy). This will require the input of scientists from diverse research domains, making this field a resolutely multidisciplinary research area.

Validated biotech prototypes. Important challenges will have to be met in terms of scalability and cost to translate this research into the industrial arena. The advent of successful applications in the next years will help take the last few steps towards long-awaited demonstration of the industrial significance of G-based molecular devices.

Hammarsten initially described guanine as a "curious nucleic acid"; we would wager that he was very far from thinking that, 125 years later, scientific communities from different origins (supramolecular chemistry, polymer, soft matter, bioelectronics, catalysis and chemical biology) would become curious about this nucleic acid. One thing is certain: no one is more adventurous than the scientist who tries to follow guanine on its way across various chemical lands, along a route whose trajectory is as yet unknown. It is a fascinating, transdisciplinary chemical adventure in a yet undiscovered country from which no wanderer returns.

Published online: 27 September 2019
1. Davis, J. T. G-quartets 40 years later: from $5^{\prime}-\mathrm{GMP}$ to molecular biology and supramolecular chemistry. Angew. Chem. Int. Ed. 43, 668-698 (2004).

2. Watson, J. D. \& Crick, F. H. Molecular structure of nucleic acids. Nature 171, 737-738 (1953).

3. Hoogsteen, K. The structure of crystals containing a hydrogen-bonded complex of 1-methylthymine and 9-methyladenine. Acta Cryst. 12, 822-823 (1959).

4. Tipson, R. S. The chemistry of the nucleic acids Adv. Carbohydr. Chem. 1, 193-245 (1945).

5. Miescher, F. Hoppe-Seyler's Med-chem. Untersuch 441, 502 (1871)

6. Hammarsten, O. Zur Kenntniss der Nucleoproteide. Z. Phys. Chem. 19, 19-37 (1895).

7. Levene, P. A. \& Jacobs, W. A. Guanylic acid. Ber. Dtsch. Chem. Ges. 42, 2469-2473 (1909).

8. Bang, I. Untersuchungen über die Guanylsäure. Biochem. Z. 26, 293-311 (1910).

9. Buell, M. V. \& Perkins, M. E. Crystalline guanine nucleotide. J. Biol. Chem. 72, 21-26 (1927).

10. Gellert, M., Lipsett, M. N. \& Davies, R. D. Helix formation by guanylic acid. Proc. Natl Acad. Sci. USA 48, 2013-2018 (1962).
11. Maizels, N. G4-associated human diseases EMBO Rep. 16, 910-922 (2015).

12. Cammas, A. \& Millevoi, S. RNA G-quadruplexes: emerging mechanisms in disease. Nucleic Acids Res. 45, 1584-1595 (2017).

13. Balasubramanian, S., Hurley, L. H. \& Neidle, S. Targeting G-quadruplexes in gene promoters: a novel anticancer strategy? Nat. Rev. Drug Discov. 10, 261-275 (2011).

14. Bochman, M. L., Paeschke, K. \& Zakian, V. A. DNA secondary structures: stability and function of G-quadruplex structures. Nat. Rev. Genet. 13, 770-780 (2012)

15. Rhodes, D. \& Lipps, H. J. G-quadruplexes and their regulatory roles in biology. Nucleic Acids Res. 43, 8627-8637 (2015).

16. Hänsel-Hertsch, R., Di Antonio, M. $\delta$ Balasubramanian, S. DNA G-quadruplexes in the human genome: detection, functions and therapeutic potential. Nat. Rev. Mol. Cell Biol. 18, 279-284 (2017).

17. Kwok, C. K., Marsico, G. \& Balasubramanian, S. Detecting RNA G-quadruplexes (rG4s) in the transcriptome. Cold Spring Harb. Persp. Biol. 10 a032284 (2018)
18. Davis, J. T., Tirumala, S., Jenssen, J. R., Radler, E. $\&$ Fabris, D. Self-assembled ionophores from isoguanosine. J. Org. Chem. 60, 4167-4176 (1995).

19. Gottarelli, G., Masiero, S. \& Spada, G. P. Self-assembly in organic solvents of a deoxyguanosine derivative induced by alkali metal picrates. J. Chem. Soc. Chem. Commun. 24, 2555-2557 (1995).

20. Pinnavaia, T. et al. Alkali metal ion specificity in the solution ordering of a nucleotide, 5 '-guanosine monophosphate. J. Am. Chem. Soc. 100, 3625-3627 (1978).

21. Cai, M. et al. Binding cesium ions with nucleosides: templated self-assembly of isoguanosine pentamers. Angew. Chem. Int. Ed. 39, 1283-1285 (2000)

22. Van Leeuwen, F. W., Verboom, W., Shi, X., Davis, J. T. $\&$ Reinhoudt, D. N. Selective ${ }^{226} \mathrm{Ra}^{2+}$ ionophores provided by self-assembly of guanosine and isoguanosine derivatives. J. Am. Chem. Soc. 126 16575-16581 (2004)

23. Gubala, V., Betancourt, J. E. \& Rivera, J. M. Expanding the Hoogsteen edge of 2'-deoxyguanosine: consequences for G-quadruplex formation. Org. Lett. 6, 4735-4738 (2004). 
24. Otero, R. et al. Guanine quartet networks stabilized by cooperative hydrogen bonds. Angew. Chem. Int. Ed. 44, 2270-2275 (2005)

25. Martín-Hidalgo, M. \& Rivera, J. M. Metallo-responsive switching between hexadecameric and octameric supramolecular G-quadruplexes. Chem. Commun. 47 12485-12487 (2011).

26. Lena, S., Neviani, P., Masiero, S., Pieraccini, S. \& Spada, G. P. Triggering of guanosine self-assembly by light. Angew. Chem. Int. Ed. 49, 3657-3660 (2010).

27. González-Rodrīguez, D. et al. G-quadruplex self-assembly regulated by Coulombic interactions. Nat. Chem. 1, 151-155 (2009)

28. Reddy, G. M. et al. Co-existence of distinct supramolecular assemblies in solution and in the solid state. Chem. Eur. J. 23, 2315-2322 (2017).

29. Kaucher, M. S. \& Davis, J. T. N2, C8-disubstituted guanosine derivatives can form $\mathrm{G}$-quartets. Tetrahedron Lett. 47, 6381-6384 (2006)

30. He, Y. et al. Construction of a cross-layer linked G-octamer via conformational control: a stable G-quadruplex in $\mathrm{H}$-bond competitive solvent. Chem Sci. 10, 4192-4199 (2019).

31. Chen, L., Sakai, N., Moshiri, S. T. \& Matile, S Toward supramolecular ion channels formed by oligonucleotide analogs: Hydrophobic guanine dimers. Tetrahedron Lett. 39, 3627-3630 (1998)

32. Sidorov, V., Kotch, F. W., El-Kouedi, M. \& Davis, J. T. Toward artificial ion channels: self-assembled nanotubes from calix [4] arene-guanosine conjugates. Chem. Commun. 23, 2369-2370 (2000).

33. Cram, D. J., Jaeger, R. \& Deshayes, K. Hemicarcerands that encapsulate hydrocarbons with molecular weights greater than two hundred. J. Am. Chem. Soc. 115 10111-10116 (1993)

34. Nikan, M. \& Sherman, J. C. Template-assembled synthetic G-quartets (TASQs). Angew. Chem. Int. Ed. 47, 4900-4902 (2008)

35. Nikan, M. \& Sherman, J. C. Cation-complexation behavior of template-assembled synthetic G-quartets. J. Org. Chem. 74, 5211-5218 (2009).

36. Hightower, J. B., Olmos, D. R. \& Walmsley, J. A Supramolecular structure and polymorphism of alkali metal salts of guanosine 5'-monophosphate: SEM and NMR study. J. Phys. Chem. B 113, 12214-12219 (2009).

37. Wu, G., Kwan, I. C. M., Yan, Z., Huang, Y. \& Ye, E. On the helical structure of guanosine $5^{\prime}$-monophosphate formed at $\mathrm{pH} 5$ : is it left- or right-handed? J. Nucleic Acids 2017, 6798759 (2017)

38. Wu, G. \& Kwan, I. C. Helical structure of disodium 5 '-guanosine monophosphate self-assembly in neutral solution. J. Am. Chem. Soc. 131, 3180-3182 (2009).

39. Nakayama, S., Kelsey, I., Wang, J. \& Sintim, H. O. c-di-GMP can form remarkably stable G-quadruplexes at physiological conditions in the presence of some planar intercalators. Chem. Commun. 47, 4766-4768 (2011)

40. Nakayama, S. et al. Thiazole orange-induced c-di-GMP quadruplex formation facilitates a simple fluorescent detection of this ubiquitous biofilm regulating molecule. J. Am. Chem. Soc. 133, 4856-4864 (2011).

41. Bare, G. A. L., Liu, B. \& Sherman, J. C. Synthesis of a single G-quartet platform in water. J. Am. Chem. Soc 135, 11985-11989 (2013)

42. Gonnelli, A. et al. Small-angle X-ray scattering study of self-assembling lipophilic guanines in organic solvents: G-quadruplex formation and cation effects in cyclohexane. J. Phys. Chem. B 117, 1095-1103 (2013).

43. Kunstelj, K., Federiconi, F., Spindler, L. \& Drevenšek-Olenik, I. Self-organization of guanosine 5'-monophosphate on mica. Colloids Surf. B Biointerfaces 59, 120-127 (2007).

44. Zhang, C. et al. Solventless formation of G-quartet complexes based on alkali and alkaline earth salts on Au(111). ChemPhysChem 16, 2099-2105 (2015).

45. González-Rodrīguez, D. et al. Persistent, well-defined, monodisperse, $\pi$-conjugated organic nanoparticles via G-quadruplex self-assembly. J. Am. Chem. Soc. 132 4710-4719 (2010)

46. Gao, M. et al. Temperature and pressure limits of guanosine monophosphate self-assemblies. Sci. Rep. 7, 9864 (2017)

47. Azargun, M. \& Fridgen, T. D. Guanine tetrads an IRMPD spectroscopy, energy resolved SORI-CID and computational study of M(9-ethylguanine) $(\mathrm{M}=\mathrm{Li}, \mathrm{Na}, \mathrm{K}, \mathrm{Rb}, \mathrm{Cs})$ in the gas phase. Phys. Chem. Chem. Phys. 17, 25778-25785 (2015)

48. Azargun, M., Jami-Alahmadi, Y. \& Fridgen, T. D. The intrinsic stabilities and structures of alkali metal cationized guanine quadruplexes. Phys. Chem. Chem. Phys. 19, 1281-1287 (2017).
49. Fraschetti, C., Montagna, M., Guarcini, L., Guidoni, L. \& Filippi, A. Spectroscopic evidence for a gas-phase librating G-quartet-Na+ complex. Chem. Commun. 50 14767-14770 (2014).

50. Mudroňovă, K., Římal, V. \& Mojzeš, P. Effect of ribose versus $2^{\prime}$-deoxyribose residue in guanosine 5 '-monophosphates on formation of G-quartets stabilized by potassium and sodium cations. Vib. Spectrosc. 82, 60-65 (2016).

51. Panda, M. \& Walmsley, J. A. Circular dichroism study of supramolecular assemblies of guanosine 5'-monophosphate. J. Phys. Chem. B 115 , 6377-6383 (2011).

52. Goncharova, I., Novotná, J. \& Urbanová, M. Stacked and continuous helical self-assemblies of guanosine monophosphates detected by vibrational circular dichroism. Anal. Bioanal Chem 403, 2635-2644 (2012).

53. Kwan, I. C. M., Mo, X. \& Wu, G. Probing hydrogen bonding and ion-carbonyl interactions by solid-state ${ }^{17} \mathrm{O}$ NMR spectroscopy: G-ribbon and G-quartet. J. Am. Chem. Soc. 129, 2398-2407 (2007)

54. Wong, A., Kotch, F. W., Kwan, I. C. M., Davis, J. T. \& $\mathrm{Wu}, \mathrm{G}$. Probing the $\mathrm{Na}^{+}$binding site in a calix [4] arene-guanosine conjugate dimer by solid-state ${ }^{23} \mathrm{Na}$ NMR and quantum chemical calculation. Chem. Commun. 16, 2154-2156 (2009).

55. Mukhopadhyay, T. K. \& Datta, A. Design rules for the generation of stable quartet phases of nucleobases over two-dimensional materials. J. Phys. Chem. C 122 28918-28933 (2018)

56. Šponer, J. et al. Folding of guanine quadruplex molecules-funnel-like mechanism or kinetic partitioning? An overview from MD simulation studies. Biochim. Biophys. Acta 1861, 1246-1263 (2017).

57. Gresh, N. et al. Channeling through two stacked guanine quartets of one and two alkali cations in the $\mathrm{Li}^{+}, \mathrm{Na}^{+}, \mathrm{K}^{+}$, and $\mathrm{Rb}^{+}$series. Assessment of the accuracy of the SIBFA anisotropic polarizable molecular mechanics potential. J. Phys. Chem. B 121 , 3997-4014 (2017).

58. Zaccaria, F. Paragi, G. \& Fonseca Guerra, C. F. The role of alkali metal cations in the stabilization of guanine quadruplexes: why $\mathrm{K}^{+}$is the best. Phys. Chem Chem. Phys. 18, 20895-20904 (2016).

59. Paragi, G. \& Fonseca Guerra, C. Cooperativity in the self-assembly of the guanine nucleobase into quartet and ribbon structures on surfaces. Chem. Eur. J. 23 3042-3050 (2017).

60. Kotch, F. W. et al. Water-mediated association provides an ion pair receptor. J. Am. Chem. Soc. 125 15140-15150 (2003).

61. Davis, J. T., Okunola, O. \& Quesada, R. Recent advances in the transmembrane transport of anions. Chem. Soc. Rev. 39, 3843-3862 (2010).

62. Kaucher, M. S., Harrell, W. A. \& Davis, J. T. A unimolecular G-quadruplex that functions as a synthetic transmembrane $\mathrm{Na}^{+}$transporter. J. Am. Chem. Soc. 128, 38-39 (2006).

63. Sutyak, K. B., Lee, W., Zavalij, P. V., Gutierrez, O. $\&$ Davis, J. T. Templating and catalyzing [2+2] photocycloaddition in solution using a dynamic G-quadruplex. Angew. Chem. Int. Ed. 57 17146-17150 (2018).

64. Sakai, N. et al. Dendritic folate rosettes as ion channels in lipid bilayers. J. Am. Chem. Soc. 128 2218-2219 (2006)

65. Ma, L., Melegari, M Colombini, M \& Davis, J. T. Large and stable transmembrane pores from guanosine-bile acid conjugates. J. Am. Chem. Soc 130, 2938-2939 (2008)

66. Kumar, Y. P. et al. Triazole-tailored guanosine dinucleosides as biomimetic ion channels to modulate transmembrane potential. Chem. Eur. J. 20 , 3023-3028 (2014)

67. Kumar, Y. P., Das, R. N., Schütte, O. M., Steinem, C. \& Dash, J. Bis-triazolyl diguanosine derivatives as synthetic transmembrane ion channels. Nat. Protoc. 11, 1039-1056 (2016)

68. Ghosh, A., Parasar, B., Bhattacharyya, T. \& Dash, J. Chiral carbon dots derived from guanosine 5'-monophosphate form supramolecular hydrogels. Chem Commun 52, 11159-11162 (2016).

69. Li, Z. \& Mirkin, C. A. G-quartet-induced nanoparticle assembly. J. Am. Chem. Soc. 127, 11568-11569 (2005).

70. Wong, A., Ida, R., Spindler, L. \& Wu, G. Disodium guanosine 5 '-monophosphate self-associates into nanoscale cylinders at $\mathrm{pH}$ 8: a combined diffusion NMR spectroscopy and dynamic light scattering study. J. Am. Chem. Soc. 127, 6990-6998 (2005)
71. Hu, D., Ren, J. \& Qu, X. Metal-mediated fabrication of new functional G-quartet-based supramolecular nanostructure and potential application as controlled drug release system. Chem. Sci. 2, 1356-1361 (2011).

72. Pu, F., Wu, L., Ran, X., Ren, J. \& Qu, X. G-quartetbased nanostructure for mimicking light-harvesting antenna. Angew. Chem. Int. Ed. 54, 892-896 (2015).

73. Wu, Y.-L., Brown, K. E. \& Wasielewski, M. R. Extending photoinduced charge separation lifetimes by using supramolecular design: guanine-perylenediimide G-quadruplex. J. Am. Chem. Soc. 135, 13322-13325 (2013).

74. Wu, Y.-L. et al. G-quadruplex organic frameworks. Nat Chem. 9, 466-472 (2017).

75. Nakayama, S., Roelofs, K., Lee, V. T. \& Sintim, H. O. A C-di-GMP-proflavine-hemin supramolecular complex has peroxidase activity-implication for a simple colorimetric detection. Mol. Biosyst. 8 , 726-729 (2012)

76. Li, Y. \& Sen, D. A catalytic DNA for porphyrin metallation. Nat. Struct. Biol. 3, 743-747 (1996).

77. Li, Y. $\&$ Sen, D. Toward an efficient DNAzyme. Biochemistry 36, 5589-5599 (1997).

78. Travascio, P., Li, Y. \& Sen, D. DNA-enhanced peroxidase activity of a DNA aptamer-hemin complex. Chem. Biol. 5, 505-517 (1998).

79. Travascio, P., Witting, P. K., Mauk, A. G. \& Sen, D The peroxidase activity of a hemin-DNA oligonucleotide complex: free radical damage to specific guanine bases of the DNA. J. Am . Chem. Soc 123, 1337-1348 (2001)

80. Stefan, L., Denat, F. \& Monchaud, D. Insights into how nucleotide supplements enhance the peroxidase-mimicking DNAzyme activity of the G-quadruplex/hemin system. Nucleic Acids Res. 40 8759-8772 (2012).

81. Yamamoto, Y. et al. Characterization of heme-DNA complexes composed of some chemically modified hemes and parallel G-quadruplex DNAs. Biochemistry 54, 7168-7177 (2015)

82. Chen, J. et al. How proximal nucleobases regulate the catalytic activity of G-quadruplex/hemin DNAzymes. ACS Catal. 8, 11352-11361 (2018).

83. Sen, D. \& Poon, L. C. RNA and DNA complexes with hemin [Fe(III) heme] are efficient peroxidases and peroxygenases: how do they do it and what does it mean? Crit. Rev. Biochem. Mol. Biol. 46, 478-492 (2011).

84. Wang, F., Lu, C.-H. \& Willner, I. From cascaded catalytic nucleic acids to enzyme-DNA nanostructures: controlling reactivity, sensing, logic operations, and assembly of complex structures. Chem. Rev. 114, 2881-2941 (2014).

85. Mergny, J.-L. \& Sen, D. DNA quadruple helices in nanotechnology. Chem. Rev. 119, 6290-6325 (2019).

86. Flack, T. et al. Prefolded synthetic G-quartets display enhanced bioinspired properties. Chem. Eur. J. 22, 1760-1767 (2016).

87. Stefan, L., Xu, H.-J., Gros, C. P., Denat, F $\delta$ Monchaud, D. Harnessing nature's insights: synthetic small molecules with peroxidase-mimicking DNAzyme properties. Chem. Eur. J. 17, 10857-10862 (2011).

88. Harraz, D. M. \& Davis, J. T. A self-assembled peroxidase from 5'-GMP and heme. Chem. Commun. 54, 1587-1590 (2018)

89. Bhattacharyya, T., Kumar, Y. P. \& Dash, J. Supramolecular hydrogel inspired from DNA structures mimics peroxidase activity. ACS Biomat. Sci. Eng. 3, 2358-2365 (2017).

90. Zhong, R. et al. Self-assembly of enzyme-like nanofibrous G-molecular hydrogel for printed flexible electrochemical sensors. Adv. Mater. 30, 1706887 (2018).

91. de Gennes, P. G. Soft matter (Nobel lecture). Angew. Chem. Int. Ed. 31, 842-845 (1992).

92. Nagel, S. R. Experimental soft-matter science. Rev. Mod. Phys. 89, 025002 (2017)

93. Peters, G. M. \& Davis, J. T. Supramolecular gels made from nucleobase, nucleoside and nucleotide analogs. Chem. Soc. Rev, 45, 3188-3206 (2016)

94. Gottarelli, G. et al. The self-assembly of lipophilic guanosine derivatives in solution and on solid surfaces. Chem. Eur. J. 6, 3242-3248 (2000)

95. Mezzina, E. et al. The self-assembly of a lipophilic guanosine nucleoside into polymeric columnar aggregates: the nucleoside structure contains sufficient information to drive the process towards a strikingly regular polymer. Chem. Eur. J. 7, 388-395 (2001). 
96. Pieraccini, S. et al. Columnar lyomesophases formed in hydrocarbon solvents by chiral lipophilic guanosine-alkali metal complexes. Chirality 13, 7-12 (2001).

97. Giorgi, T. et al. Gel-like lyomesophases formed in organic solvents by self-assembled guanine ribbons. Chem. Eur. J. 8, 2143-2152 (2002).

98. Gan, K. P., Yoshio, M., Sugihara, Y. \& Kato, T. Guanine-oligothiophene conjugates: liquid-crystalline properties, photoconductivities and ion-responsive emission of their nanoscale assemblies. Chem. Sci. 9, 576-585 (2018)

99. Meng, L., Liu, K., Mo, S., Mao, Y. \& Yi, T. From G-quartets to G-ribbon gel by concentration and sonication control. Org. Biomol. Chem. 11, 1525-1532 (2013)

100. Wang, X. et al. Reversible organogels triggered by dynamic $\mathrm{K}^{+}$binding and release. J. Colloid Interface Sci. 353, 412-419 (2011).

101. Pieraccini, S., Masiero, S., Pandoli, O., Samorī, P. \& Spada, G. P. Reversible interconversion between a supramolecular polymer and a discrete octameric species from a guanosine derivative by dynamic cation binding and release. Org. Lett. 8, 3125-3128 (2006)

102. Spada, G. P. et al. Guanosine-based hydrogen-bonded scaffolds: controlling the assembly of oligothiophenes. Adv. Mater. 20, 2433-2438 (2008).

103. Mihai, S., Le Duc, Y., Cot, D. \& Barboiu, M. Sol-gel selection of hybrid G-quadruplex architectures from dynamic supramolecular guanosine libraries. J. Mat Chem. 20, 9443-9448 (2010).

104. Meffre, A., Petit, E., Cot, D. \& Barboiu, M. Kinetic selection of polymeric guanosine architectures from dynamic supramolecular libraries. C. R. Chim. 18, 960-965 (2015)

105. Zhang, J. et al. GMP-quadruplex-based hydrogels stabilized by lanthanide ions. Sci. China Chem. 61 604-612 (2018)

106. Carducci, F., Yoneda, J. S., Itri, R. \& Mariani, P. On the structural stability of guanosine-based supramolecular hydrogels. Soft Matter 14 2938-2948 (2018)

107. Nava, G. et al. Quadruplex knots as network nodes: nano-partitioning of guanosine derivates in supramolecular hydrogels. Soft Matter 15 2315-2318 (2019)

108. Yu, Y., Nakamura, D., DeBoyace, K., Neisius, A. W. $\&$ McGown, L. B. Tunable thermoassociation of binary guanosine gels. J. Phys. Chem. B 112, 1130-1134 (2008).

109. Buerkle, L. E., Li, Z., Jamieson, A. M. \& Rowan, S. J. Tailoring the properties of guanosine-based supramolecular hydrogels. Langmuir 25, 8833-8840 (2009).

110. Adhikari, B., Shah, A. \& Kraatz, H.-B. Self-assembly of guanosine and deoxy-guanosine into hydrogels: monovalent cation guided modulation of gelation, morphology and self-healing properties. J. Mat. Chem. B 2, 4802-4810 (2014)

111. Tang, F. et al. Developing a self-healing supramolecular nucleoside hydrogel based on guanosine and isoguanosine. Chem. Asian. J. 13, 1962-1971 (2018).

112. Peters, G. M. et al. $\mathrm{A} \mathrm{G}_{4} \cdot \mathrm{K}^{+}$hydrogel stabilized by an anion. J. Am. Chem. Soc. 136, 12596-12599 (2014).

113. Peters, G. M., Skala, L. P. \& Davis, J. T. A molecular chaperone for G4-quartet hydrogels. J. Am. Chem. Soc. 138, 134-139 (2016).

114. Pieraccini, S. et al. Playing supramolecular dominoe with light: building and breaking a photoreversible G-quadruplex made from guanosine, boric acid and an azobenzene. Org. Biomol. Chem. 17, 2759-2769 (2019).

115. Ghoussoub, A. \& Lehn, J.-M. Dynamic sol-gel interconversion by reversible cation binding and release in G-quartet-based supramolecular polymers. Chem Commun 46, 5763-5765 (2005).

116. Buchs, B. et al. Release of bioactive volatiles from supramolecular hydrogels: influence of reversible acylhydrazone formation on gel stability and volatile compound evaporation. Org. Biomol. Chem. 9 , 2906-2919 (2011)

117. Buhler, E., Sreenivasachary, N., Candau, S.-J. \& Lehn, J.-M. Modulation of the supramolecular structure of G-quartet assemblies by dynamic covalent decoration J. Am. Chem. Soc. 129, 10058-10059 (2007).

118. Sreenivasachary, N. \& Lehn, J.-M. Gelation-driven component selection in the generation of constitutional dynamic hydrogels based on guanine-quartet formation. Proc. Natl Acad. Sci. USA 102, 5938-5943 (2005)

119. Arnal-Hérault, C. et al. Functional G-quartet macroscopic membrane films. Angew. Chem. Int. Ed. 46, 8409-8413 (2007)

120. Dash, J Patil, A J., Das, R N Dowdall, F L \& Mann, S. Supramolecular hydrogels derived from silver ion-mediated self-assembly of 5 '-guanosine monophosphate. Soft Matter 7, 81 20-8126 (2011)

121. Feng, H. et al. Silver ions blocking crystallization of guanosine-based hydrogel for potential antimicrobia applications. RSC Adv. 8, 15842-15852 (2018).

122. Sreenivasachary, N. \& Lehn, J.-M. Structural selection in G-quartet-based hydrogels and controlled release of bioactive molecules. Chem. Asian J. 3, 134-139 (2008).

123. Das, R. N., Kumar, Y. P., Pagoti, S., Patil, A. J. \& Dash, J. Diffusion and birefringence of bioactive dyes in a supramolecular guanosine hydrogel. Chem. Eur. J. 18, 6008-6014 (2012)

124. Plank, T. N. \& Davis, J. T. A G $\cdot \mathrm{K}^{+}$hydrogel that self-destructs. Chem. Commun. 52, 5037-5040 (2016).

125. Venkatesh, V. et al. Supramolecular photoactivatable anticancer hydrogels. J. Am. Chem. Soc. 139 5656-5659 (2017).

126. Buerkle, L. E., von Recum, H. A. \& Rowan, S. J. Toward potential supramolecular tissue engineering scaffolds based on guanosine derivatives. Chem. Sci. 3 564-572 (2012)

127. Rotaru, A. et al. G-quartet hydrogels for effective cell growth applications. Chem. Commun. 53, 12668-12671 (2017).

128. Shendure, J. et al. DNA sequencing at 40: past, present and future. Nature 550, 345-353 (2017)

129. Chambers, V. S. et al. High-throughput sequencing of DNA G-quadruplex structures in the human genome. Nat. Biotechnol. 33, 877-881 (2015)

130. Hänsel-Hertsch, R. et al. G-quadruplex structures mark human regulatory chromatin. Nat. Genet. 48 1267-1272 (2016).

131. Kwok, C. K Marsico, G Sahakyan, A B. Chambers, V. S. \& Balasubramanian, S. rG4-seq reveals widespread formation of G-quadruplex structures in the human transcriptome. Nat. Methods 13, 841-844 (2016)

132. Yang, S. Y. et al. Transcriptome-wide identification of transient RNA G-quadruplexes in human cells. Nat. Commun. 9, 4730 (2018).

133. Monchaud, D. \& Teulade-Fichou, M.-P. A hitchhiker's guide to G-quadruplex ligands. Org. Biomol. Chem. 6 627-636 (2008).

134. Neidle, S. Quadruplex nucleic acids as targets for anticancer therapeutics. Nat. Rev. Chem. 1, 0041 (2017).

135. Neidle, S. Quadruplex nucleic acids as novel therapeutic targets. J. Med. Chem. 59, 5987-6011 (2016).

136. Drygin, D. et al. Anticancer activity of CX-3543 a direct inhibitor of rRNA biogenesis. Cancer Res. 69 7653-7661 (2009).

137. Moore, M. J. B. et al. Trisubstituted acridines as $\mathrm{G}$-quadruplex telomere targeting agents. Effects of extensions of the 3,6- and 9-side chains on quadruplex binding, telomerase activity, and cell proliferation. J. Med. Chem. 49, 582-599 (2006).

138. De Cian, A., DeLemos, E., Mergny, J.-L., Teulade-Fichou, M.-P. \& Monchaud, D. Highly efficient G-quadruplex recognition by bisquinolinium compounds. J. Am. Chem. Soc. 129, 1856-1857 (2007).

139. Rodriguez, R. et al. A novel small molecule that alters shelterin integrity and triggers a DNA-damage response at telomeres. J. Am. Chem. Soc. 130 15758-15759 (2008).

140. Stefan, L. et al. DOTASO as a prototype of nature-inspired G-quadruplex ligand. Chem. Commun. 47, 4992-4994 (2011)

141. Lejault, P. et al. The scope of application of macrocyclic polyamines beyond metal chelation. Eur. J. Org. Chem. https://doi.org/10.1002/ejoc. 201900870 (2019).

142. Haudecoeur, R., Stefan, L., Denat, F. \& Monchaud, D. A model of smart G-quadruplex ligand. J. Am. Chem. Soc. 135, 550-553 (2013).

143. Newman, M. et al. The G-quadruplex-specific RNA helicase DHX36 regulates p53 pre-mRNA 3'-end processing following UV-induced DNA damage. J. Mol. Biol. 429, 3121-3131 (2017).
144. Laguerre, A. et al. A twice-as-smart synthetic G-quartet: PyroTASO is both a smart quadruplex ligand and a smart fluorescent probe. J. Am. Chem. Soc. 136, 12406-12414 (2014).

145. Zhou, J. et al. Computational understanding and experimental characterization of twice-as-smart quadruplex ligands as chemical sensors of bacterial nucleotide second messengers. Sci. Rep. 6, 33888 (2016).

146. Laguerre, A. et al. Visualization of RNA-quadruplexes in live cells. J. Am. Chem. Soc. 137, 8521-8525 (2015).

147. Laguerre, A., Wong, J. M. Y. \& Monchaud, D. Direct visualization of both DNA and RNA quadruplexes in human cells via an uncommon spectroscopic method. Sci. Rep. 6, 32141 (2016).

148. Roux, A. et al. Small-molecule affinity capture of DNA RNA quadruplexes and their identification in vitro and in vivo through the G4RP protocol. Nucleic Acids Res. 47, 5502-5510 (2019).

149. Rivera-Sánchez, Md. C., García-Arriaga, M. Hobley, G., Morales-de-Echegaray, A. V. \& Rivera, J. M Small-molecule-based self-assembled ligands for G-quadruplex DNA surface recognition. ACS Omega 2 , 6619-6627 (2017).

150. Pavan Kumar, Y. et al. Fluorescent dansyl-guanosine conjugates that bind $c-M Y C$ promoter G-quadruplex and downregulate $c-M Y C$ expression. ChemBioChem 17, 388-393 (2016)

151. Ross, P. et al. Regulation of cellulose synthesis in Acetobacter xylinum by cyclic diguanylic acid. Nature 325, 279-281 (1987).

152. Monchaud, D. in DNA in Supramolecular Chemistry and Nanotechnology Ch. 3.5 (eds Stulz, E. \& Clever, G. H.) 229-246 (Wiley, 2015).

153. Gilli, G., Bellucci, F., Ferretti, V. \& Bertolasi, V. Evidence for resonance-assisted hydrogen bonding from crystal-structure correlations on the enol form of the. beta.-diketone fragment. J. Am. Chem. Soc. 111, 1023-1028 (1989).

154. Fonseca Guerra, C., Zijlstra, H., Paragi, G. \& Bickelhaupt, F. M. Telomere structure and stability: covalency in hydrogen bonds, not resonance assistance, causes cooperativity in guanine quartets Chem. Eur. J. 17, 12612-12622 (2011).

155. Davis, J. T. \& Spada, G. P. Supramolecular architectures generated by self-assembly of guanosine derivatives. Chem. Soc. Rev. 36, 296-313 (2007).

156. Dahm, R. Discovering DNA: Friedrich Miescher and the early years of nucleic acid research. Hum. Gene 122, 565-581 (2008).

157. Avery, O. T., MacLeod C. M. \& McCarty, M. Studies on the chemical nature of the substance inducing transformation of pneumococcal types. J. Exp. Med. 79, 137-158 (1944).

158. Crick, F. H. On protein synthesis. Symp. Soc. Exp. Biol. 12, 138-163 (1958)

159. Rodriguez, R. et al. Small-molecule-induced DNA damage identifies alternative DNA structures in human genes. Nat. Chem. Biol. 8, 301-310 (2012).

160. Biffi, G., Tannahill, D., McCafferty, J. \& Balasubramanian, S. Quantitative visualization of DNA G-quadruplex structures in human cells. Nat. Chem. 5, 182-186 (2013).

\section{Acknowledgements}

LS and D.M. thank the Centre National de la Recherche Scientifique (CNRS) for funding. D.M. thanks the Agence Nationale de la Recherche (ANR-17-CE17-0010-01), the European Research Council (H2020-MSCA-IF-2016-750368), the Université de Bourgogne, Conseil Régional de Bourgogne (PARI) and the European Union (Pharmaco-imagerie et agents therranostiques, PO FEDER-FSE Bourgogne 2014-2020 programme) for financial support. The authors also thank their collaborators for the daily passionate scientific discussions and all scientists worldwide involved in the fascinating field of research, to make it lively, thrilling and always moving.

\section{Author contributions}

All authors contributed equally to the preparation of this manuscript.

\section{Competing interests}

The authors declare no competing interests.

\section{Publisher's note}

Springer Nature remains neutral with regard to jurisdictional claims in published maps and institutional affiliations. 